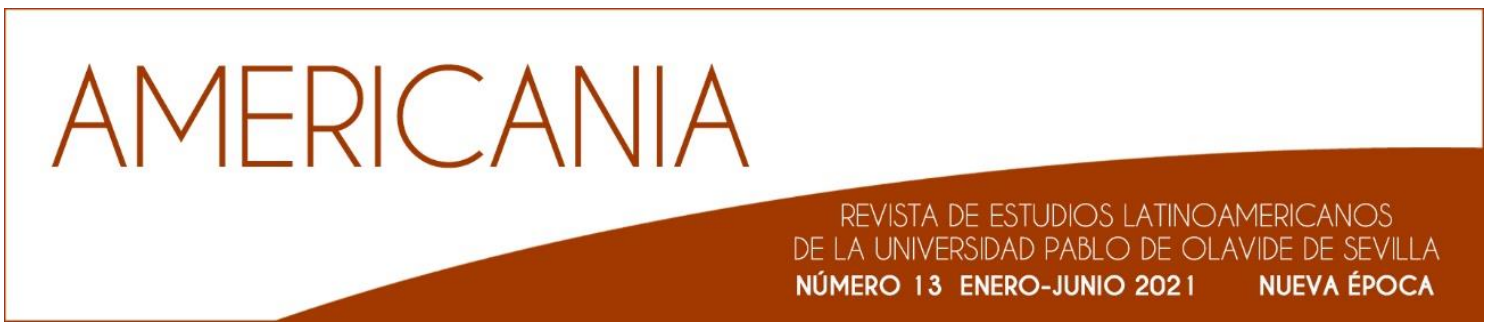

\title{
ESTADO REPUBLICANO Y SUJETO INDÍGENA
}

\section{La experiencia militar en el Altiplano Andino de la provincia de Jujuy \\ (Argentina, 1830 - 1860)}

\section{Resumen}

En este artículo exploramos la experiencia militar de las poblaciones indígenas de la Puna de Jujuy durante el ciclo de las guerras civiles decimonónicas de la Argentina. Nos proponemos examinar la composición numérica y variación de las tropas de la región durante cuatro décadas, así como las causales y las proyecciones de un motín protagonizado en el año 1837. Sostenemos que ante un proceso de militarización concreto y tangible se sustentaron actos de resistencia a la milicia y trascendentales negociaciones. Trabajamos un corpus documental diverso de los Archivos Históricos de la Provincia de Jujuy y Salta y del Archivo General de la Nación (Argentina).

Palabras Clave

Militarización - Siglo XIX - Guerras Civiles - Sujeto Político Indígena - Puna/Jujuy

1 Doctora en Historia por la Universidad Nacional de Tucumán. Investigadora Independiente en el Consejo Nacional de Investigaciones Científicas y Técnicas de la Argentina (CONICET) y Docente de la Universidad Nacional de Jujuy como Profesora Asociada Ordinaria de la Cátedra de Historia Económica y Social y docente responsable en la Maestría en Políticas Públicas y Desarrollo en Contextos Regionales, de la Facultad de Ciencias Económicas (UNJu). 


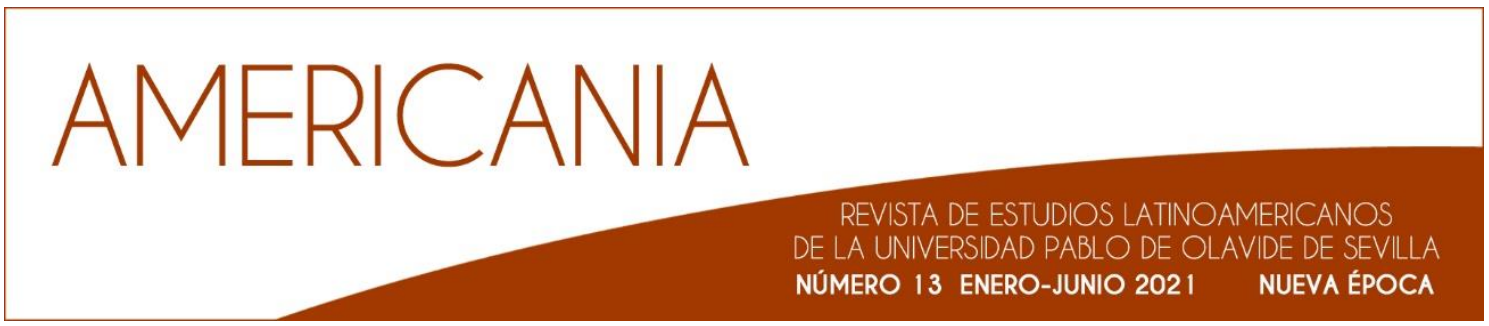

REPUBLICAN STATE AND INDIGENOUS SUBJECT

The military experience in the Andean Altiplano

of the province of Jujuy (Argentina, 1830 -1860)

\begin{abstract}
In this article we explore the military experience of the indigenous populations of the Puna de Jujuy during the cycle of nineteenth-century civil wars in Argentina. We propose to examine the numerical composition and variation of the troops in the region over four decades, as well as the causes and projections of a mutiny staged in 1837. We maintain that in the face of a concrete and tangible militarization process, acts of resistance to the militia and far-reaching negotiations were sustained. We work on a diverse documentary corpus from the Historical Archives of the Province of Jujuy and Salta and from the General Archive of the Nation (Argentina).
\end{abstract}

Key Words

Militarization - $19^{\text {th }}$ Century - Civil Wars - Indigenous Political Subject - Puna/Jujuy 


\section{Introducción}

Las constantes guerras libradas durante el siglo XIX en Latinoamérica, en el marco de conformación de los Estados nacionales, originaron procesos de militarización con trascendentales consecuencias. En la célebre obra Revolución y Guerra, de Halperín Donghi (1979), la militarización se entiende, por lo menos, en una triple dimensión: la carrera militar como vía de acceso directo al ejercicio del poder por parte de la élites que condujeron la Revolución (en el sentido que fue una vía para la legitimidad política); la proyección de la organización de los ejércitos a partir de la contienda independentista como modelo de organización de la sociedad en conjunto (es decir, una militarización de la política); y, por último, como la creación de una fuerza de guerra muy numerosa que extendió el servicio de las armas a sectores sociales más amplios e inéditos².

En conexión con ese concepto, realimentado por el desarrollo de nuevas vertientes historiográficas, el estudio de la guerra se aborda como un fenómeno de alto impacto sociopolítico porque modeló la vida de diversos colectivos sociales ${ }^{3}$. Entre las directrices trazadas para el análisis cuenta la inclusión de los sectores populares en las filas del ejército, como parte del juego político abierto y de los proyectos republicanos edificados. De ese conjunto de estudios derivan nociones, que nos interesan puntualmente, como la de 'sujeto político indígena'. La concepción de 'sujeto político indígena', básicamente, propone el reconocimiento de la capacidad de acción y protagonismo de este grupo étnico en la construcción del orden republicano y liberal decimonónico, en contraste con una línea historiográfica que directamente no los considera en el análisis o que solo los interpreta como extraños, clientes o víctimas de ese proceso 4.

De esa manera, frente a una visión dominante por mucho tiempo de 'vacío político' de los sectores indígenas, la nueva producción demuestra que la experiencia

2 Para un análisis de los sentidos que la historiografía asigna a este concepto ver Rabinovich, Alejandro, "La militarización del Río de la Plata, 1810-1820. Elementos cuantitativos y conceptuales para un análisis", Boletín del Instituto de Historia Argentina y Americana Dr. Emilio Ravignani, №37, 2012, 11-42.

3 Fradkin, Raúl, “Cultura política y acción colectiva en Buenos Aires (1806-1829): Un ejercicio de exploración”, en Fradkin, Raúl, ed., ¿Y el pueblo dónde está? Contribuciones para una historia popular de la revolución de independencia en el Río de la Plata, Prometeo, Buenos Aires, 2008, 27-66. Morán, Daniel, "La historiografía de la revolución. La participación plebeya durante las guerras de independencia en el Perú y el Río de la Plata", Nuevo Mundo Mundos Nuevos. 2011, http://nuevomundo.revues.org/61404 (Consultado el 6 de octubre de 2017).

4 Quijada, Mónica, "La caja de Pandora. El sujeto político indígena en la construcción del orden liberal", Historia Contemporánea, N3, 2006, 605-637. 
republicana no sustrajo su capacidad política, la cual puede rastrearse y volverse observable a partir de redefinir lo político y examinarse desde las escalas locales 5 . De seguro, se trata de categorías y principios que responden al tipo de problemas y razonamientos que planteamos en este estudio. En esa perspectiva, tanto los estudios de Méndez para la región de Huanta, en Perú, como los propios de Irurozqui para Bolivia, evidencian a través de una precisa lectura de los eventos bélicos y los actores protagónicos la puesta en práctica de una ciudadanía elemental (la del 'ciudadano armado') y la acción pública de los indígenas, quienes desde los espacios creados por las guerras negociaron derechos y obligaciones con el Estado6.

En este artículo situaremos el estudio de similares procesos de guerra y militarización en la Puna jujeña7, ya que en el siglo XIX ese territorio condensaba el escenario característico de las sociedades andinas, con una numerosa y perdurable población indígena repartida y sujetada a grandes haciendas en calidad de colonos, y con presencia (o reminiscencia) de derechos de propiedad comunal. Ese universo vivió el proceso de edificación de los Estados nacionales republicanos resignificando su mundo de derechos y deberes coloniales con los entonces surgidos de la nueva condición de 'ciudadanos' en el ordenamiento liberal, entre ellos (como queda dicho) los asociados a la figura de 'ciudadano armado'.

En primer lugar, debemos precisar que la historia de Jujuy en el siglo XIX transcurrió casi en un estado de guerra permanente. La provincia fue teatro de operaciones del Ejército Auxiliar del Norte y la Guerra Gaucha durante las luchas por la Independencia, hasta 18258. Luego fue escenario central de actuación de las

5 Walker, Charles, “Los indios en la transición de colonia a república: ¿Base social de la modernización política?”, en Urbano, Henrique, ed., Tradición y modernidad en los Andes, Centro de Estudios Regionales Andinos "Bartolomé de Las Casas", Cuzco, 1997, 1-14.

6 Méndez, Cecilia, "Tradiciones liberales en los Andes o la ciudadanía por las armas: campesinos y militares en la formación del estado peruano", en Irurozqui Victoriano, Marta, ed., La mirada esquiva. Reflexiones históricas sobre la interacción del estado y la ciudadanía en los Andes (Bolivia, Ecuador y Perú), siglo XIX, Consejo Superior de Investigaciones Científicas, Madrid, 2005, 125-153, 149. Irurozqui, Marta, “¿Ciudadanos armados o traidores a la patria? Participación indígena en las revoluciones bolivianas de 1870 y 1899", Iconos. Revista de Ciencias Sociales, $N^{\circ} 26,2006,35-46,44-45$.

7 La porción del altiplano de los Andes Centrales que se extiende por la provincia de Jujuy es una meseta de altura por encima de los 3.000 metros sobre el nivel del mar, un 'desierto' frío y seco, ubicado en la frontera noroeste de la Argentina, limítrofe con Bolivia y Chile.

8 En la actual jurisdicción de la Argentina se considera 'guerra de independencia' al conflicto militar contra los españoles y otros realistas, que se extendió a lo largo de la década que va entre 1810 y 1820 . La contienda se inició con las expediciones que la Junta Gubernativa de Buenos Aires (1810) envió al interior del territorio, al Alto Perú y Paraguay para garantizarse obediencia al grupo revolucionario. La fuerza militar que tuvo como teatro de operaciones las provincias que ahora conforman el Noroeste de la Argentina, entre ellas Jujuy, y los departamentos del sur de la actual república de Bolivia se denominó Ejército Auxiliar del Norte. En ese escenario y contexto, los embates de las fuerzas realistas procedentes del Alto Perú también comenzaron a ser repelidas por milicias locales 
milicias unitarias y federales; procuró también por las armas su autonomía de la vecina provincia de Salta en la década de 1830; se colocó en los años 40 en el bando de la Coalición del Norte y tras sus derrota conformó un régimen colaboracionista de la federación rosista en manos de Mariano Iturbe, gobernador de Jujuy en varios intervalos entre 1838-1852. A ello se sumó el enfrentamiento de la Confederación argentina con la peruano boliviana entre 1837 y 18389 . Desde 1851 operó un cambio de la situación política, también con uso de la violencia, que se manifestó en el relevo de la cartera gubernativa alineada a Juan Manuel de Rosas y el ascenso de la que comenzó a secundar la caída de este régimen, inaugurando el proceso abierto a Caseros $^{10}$. En el concierto nacional, a partir de 1861 la línea política de Jujuy secundó el gobierno liberal del presidente Bartolomé Mitre (1862-1868). No obstante, un conjunto de provincias defensoras del federalismo produjo levantamientos contra el gobierno central de Mitre, como la montonera del Chacho Peñaloza, en1862 y 1863 , y la acaudillada por Felipe Varela en 1866-1867. Esta última irradió en la provincia de

y fuerzas irregulares de Salta y de Jujuy al mando de Martín Miguel de Güemes, cuyo accionar se denomina Guerra Gaucha (1814-1825), en función del nombre que recibieron los paisanos alistados en estas fuerzas (gauchos) y la táctica de guerrillas empleada (Mata de López, Sara, "Guerra, Militarización y Poder. Ejército y Milicia en Salta y en Jujuy. 1810- 1816", Anuario IEHS, 24, 2009, 279-298; Di Meglio, Gabriel, "La Guerra de Independencia en la Historiografía Argentina", Plataforma del Programa Interuniversitario de Historia Política, N. 7, 2010, 1-26).

9 Conti, Viviana, 2006, "De las Guerras de la Independencia a la Organización del Estado. 1810-1852", en Teruel, Ana y Lagos, Marcelo, dir., Jujuy en la Historia. De la colonia al siglo XX, EdiUnju, Jujuy, 85-173. Un amplio conjunto de conflictos armados que tuvieron lugar entre los años 1814 y 1880 en la jurisdicción de la actual Argentina se conocen como 'guerras civiles'. Una fase de esos enfrentamientos, entre 1828 y 1831 , en el que combatieron los dos partidos que se disputaban el control territorial y político, los unitarios y federales, las jurisdicciones del Salta y Jujuy integraron el bando unitario en 1830, tras sellar un acuerdo junto a las provincias Córdoba, La Rioja, Mendoza, Catamarca, San Luis y Tucumán que se denominó Liga del Interior. En 1831 triunfó el ejército federal, iniciado una etapa de predominio de esta línea política y de hegemonía de la provincia de Buenos Aires signada por su principal líder político, Juan Manuel de Rosas (Gobernador de Buenos Aires entre 1829-1832 y 1835-1852). El orden de facto instituido entonces fue el de una Confederación de estados independientes, las provincias, unidos mediante pactos, quienes delegaban la representación de las relaciones exteriores en la persona del gobernador porteño. El equilibrio político ideado por Rosas atravesó una nueva etapa de crisis entre 1838 y 1841, en distintos frentes. Así, en un conjunto de provincias de la Confederación que no eran afectas al avance del federalismo rosista surtió un nuevo acuerdo y unión, la Liga o Coalición del Norte, el que también integró la provincia de Jujuy. Tras ser vencidos en las campañas libradas en representación de ésta, conducidas por Gregorio Araoz de Lamadrid y Juan Lavalle, se produjo un endurecimiento del régimen rosista a los opositores, asentándose una época de uniformidad política federal en las provincias (Paz, Gustavo, Las Guerras Civiles (1820-1870), Eudeba, 2007, 19-37). Paralelamente, ejerciendo Rosas las prerrogativas cedidas para el manejo de las relaciones exteriores, otra lucha librada en ese momento fue la guerra que las provincias de la Confederación Argentina emprendieron contra los ejércitos de Perú y Bolivia, unidos en una confederación, al mando del mariscal Andrés de Santa Cruz (presidente de Bolivia desde 1829 y Protector de la Confederación Peruano-Boliviana desde 1836). El teatro de esta guerra fueron las provincias del extremo Norte: Tucumán, Salta y Jujuy.

10 En la Batalla de Caseros (3/02/1852) fue vencido el ejército de Rosas, por una fuerza opositora al mando de Justo José de Urquiza (gobernador de la provincia de Entre Ríos), que desarticuló el sistema político de Rosas, vigente desde 1835 y favoreció el inicio del proceso definitivo de unión de las provincias y conformación del Estado naciona Argentino. 
Jujuy alcanzando a los departamentos de la Puna (en 1867 el pueblo de Yavi fue ocupado por el ejército varelista) ${ }^{11}$.

¿Cómo se involucraron los pobladores de la Puna en estos sucesos y procesos? La bibliografía existente ha centrado el análisis especialmente en uno de esos hechos, la Guerra de la Confederación Peruano-Boliviana (1836-1839). Así, para los relatos de tinte épico y fundamentalista del mito de la 'nación' la fuerza movilizada entonces fue mínima, estaba constituida por 'voluntarios', sin instrucción. Esta historiografía tradicional desconoce cualquier proceso de militarización positiva en la Puna y recalca un generalizado comportamiento de deslealtad, de antipatriotismo, sostenido en la activa colaboración de los pobladores con los 'invasores enemigos', tareas de espionaje, entrega de ganado, armas y otros insumos a los bolivianos, así como continuos pases a una frontera entonces cerrada y numerosas sublevaciones ${ }^{12}$.

Otros estudios entienden que, en realidad, estas acciones constituyen pruebas de la presencia de heterogéneas identidades locales en juego a raíz del trazado de una reciente frontera política-territorial entre regiones vinculadas por su historia y cultura, relaciones de parentesco y ligazón económica. De este modo las dificultades para el reclutamiento de milicias en este territorio obedecieron, según los trabajos más recientes, a un problema de identidades difusas y en construcción ${ }^{13}$. Pero, además, la mayor afinidad de los indios de la Puna con Bolivia, consideran algunos autores, pudo deberse a que en el país vecino se aseguraba el acceso a la propiedad comunal mediante el pago del tributo, siendo que ese derecho no se garantizaba ya en Jujuy ${ }^{14}$. Durante la etapa republicana la invocación al tributo colonial como prueba y/o defensa del derecho que tenían grupos indígenas a propiedades

11 Fandos, Cecilia, "Entre la Guerra del Paraguay y el levantamiento de Varela: manifestaciones socioeconómicas en Jujuy a mediados del siglo XIX", Quinto Sol, Vol. 23, № 2, 2019, 1-20.

12 Vergara, Miguel Angel, Jujuy bajo el signo federal, Edición Oficial del Gobierno de Jujuy, Imprenta del Estado, 1938. Bacile, Clemente, Una guerra poco conocida, T I, Universidad Nacional de Jujuy, San Salvador de Jujuy, (1943), 1993, 60.

13 Gil Montero, Raquel, "Guerras, hombres y ganado en la Puna de Jujuy: Comienzos del Siglo XIX", Boletín del Instituto de Historia Argentina y Americana Dr. Emilio Ravignani, N²5, 2004, 9-36; Sánchez, Matías, Nación e Identidad durante la Guerra de la Confederación Peruano Boliviana (1836-1839). La Puna y la Quebrada de Humahuaca (Jujuy, Argentina), Imprenta Lukar/ Purmamarca Ediciones, S.S de Jujuy, 2017; Davio, Marisa, "Los sectores populares militarizados en la cultura política tucumana. 1812-1852", Tesis Doctoral en Ciencias Sociales, Universidad Nacional de General Sarmiento e Instituto de Desarrollo Económico y Social (IDES), Buenos Aires, 2010, https://www.ungs.edu.ar/posgrados/sectores-populares-militarizados-en-la-cultura-politica-tucumana-1812-1854, (Consultado el 17/03/019).

14 Gil Montero, Raquel, "Guerras, hombres...", 40-41; Paz, Gustavo, "Auge y caída del 'comunismo indígena' en el Norte argentino: los Andes de Jujuy, 1830- 1900”, en Di Meglio, Gabriel y Fradkin, Raúl, comp., Hacer política. La participación popular en el siglo XIX rioplantese, Prometeo, Buenos Aires, 2013, 93-116, 95-96. 
comunales fue efectiva en muchos casos. A partir de los trabajos de Platt, sobre la región de Bolivia al Norte de Potosí, se introdujo la idea de un pacto de reciprocidad por el que las sociedades indígenas dominadas tuvieron acceso a las tierras comunales a cambio del pago de un tributo a las autoridades estatales, persistiendo en su esencia en ciertos lugares y contextos en el ordenamiento republicano hasta avanzado el siglo XIX15. En los estudios de Gil Montero, se enfatiza la flexibilidad de significados que adoptó el tributo indígena en los Andes Centromeridionales durante el siglo XIX16. En el caso de la Puna jujeña existía una discordancia entre tributo y tierras porque las poblaciones indígenas se habían diferenciado claramente durante la colonia según sus posibilidades de acceso a la tierra. Así, por un lado, existía un grupo de indios encomendados de Casabindo y Cochinoca, integrados al complejo económico del Marquesado de Tojo, que gozaban de pleno derecho a la propiedad comunal, por su condición de originarios, que fueron tributarios desde el siglo XVI. Por otro lado, las poblaciones indígenas no encomendadas eran 'forasteros sin tierras', asentados en haciendas privadas mediante el sistema de arrendamiento. Este segundo grupo, de todos modos, comenzó a ser igualmente tributario a partir de las reformas fiscales de los Borbones, en el siglo XVIII, las cuales extendieron la obligatoriedad del pago a todos los indígenas, originarios y forasteros. De tal suerte, resultó que fines del siglo XVIII la mayor parte de los indígenas de la Puna carecían de derechos sobre las tierras y eran arrendatarios. El perfil se profundizó y se generalizó en los tiempos republicanos. Entonces "Ios indígenas, antes originarios y forasteros con sus enormes diferencias internas, eran vistos como una masa homogénea de campesinos arrendatarios sin muchas distinciones"17.

También se afirma que fue reducido el peso de la militarización en la Puna durante la Guerra de Confederación Peruano-Boliviana porque para hacer frente al avance de fuerzas bolivianas en esta región se formó un solo cuerpo de milicia con pobladores puneños, el Batallón Dorrego, reclutado al comienzo de las hostilidades.

15 Platt, Tristan, Estado boliviano y ayllu andino. Tierra y tributo en el Norte de Potosí, Instituto de Estudios Peruanos, Lima, 1982.

16 Gil Montero, Raquel, "Tierras y tributo en la Puna de Jujuy. Siglos XVIII y XIX", en Farberman, Judith y Gil Montero, Raquel, comp., Los pueblos de indios del Tucumán Colonial, pervivencia y desestructuración, EDIUNju/ Universidad Nacional de Quilmes Ediciones, Argentina, 2002, 244-246.

17 Gil Montero, Raquel, "La Puna: población, recursos y estrategias", en Teruel, A. y Lagos, M., dir., Jujuy en la Historia. De la colonia al siglo XX, EDIUNJu, Jujuy, 2006, 394, 375-401. 
Luego, el resto de las operaciones no fue sostenido por soldados de la Puna sino por aquellos que procedían de los Valles Centrales y Quebrada de Humahuaca ${ }^{18}$.

Nuestra mirada amplía el margen de observación de los fenómenos que nos interesan porque incorporamos al análisis el lapso de las llamadas guerras civiles. Nos proponemos reconstruir la experiencia militar de la región, en el marco de la organización de la provincia de Jujuy y durante cuatro décadas de guerras 'civiles' y guerras 'externas' (entre los años 1830 y el decenio de 1860). Se trata de una opción que, estimamos, nos brinda mayores posibilidades de recuperar actores y acontecimientos para poner en escena, tal es nuestro propósito central, a los milicianos de la Puna. Desarrollaremos para ello dos vías de entrada a la cuestión: en primer lugar, estudiaremos la estructura militar local en cuanto a la conformación y variación numérica de las fuerzas y la normativa que reguló el ejercicio de ser soldado. Luego nos detendremos en el Motín del Batallón Dorrego (1837), revisando sus causales y su incidencia en la instrumentación de un recurso legal (la Contribución Directa 1841-1851) que eximió a los vecinos de la Puna del servicio de las armas durante un tiempo. Sostenemos que ante un proceso de militarización concreto y tangible se produjeron manifestaciones de resistencia cotidiana y resistencia armada al reclutamiento militar en la Puna, a la vez que éste provocó trascendentales negociaciones entre quienes debían brindar la prestación militar y los agentes y representantes de los gobiernos.

Por último, una mención sobre nuestras fuentes: trabajamos un corpus documental diverso compuesto por correspondencia oficial y privada, informes de asuntos militares, leyes y decretos de los Archivos Históricos de Jujuy y Salta, del Archivo de la Legislatura de Jujuy y del Archivo General de la Nación.

\section{La organización de las milicias en la Puna, alistamientos y acuartelamientos}

Durante los agitados años de la Guerra de Independencia, desde 1814 y hasta 1821, las provincias de Salta y Jujuy estuvieron sujetas al llamado 'sistema de Güemes', que introdujo una novedosa forma de movilización popular agenciada por las milicias locales, cuyo vértice de poder eran los jefes militares y el propio Martín Miguel de

18 Gil Montero, Raquel, “Guerras, hombres...”, 40. 
Güemes. El servicio de las armas configuró un espacio social de tensión, de disciplinamiento y de negociación; basado no solo en apremios (como las levas forzosas y castigos) sino también en el otorgamiento de premios y generación de estímulos materiales y simbólicos. Así, los fueros, derechos sobre tierras, exenciones impositivas a cambio del servicio, dispensas de las obligaciones privadas como el pago de los arriendos, ganancias salariales, pensiones ${ }^{19}$, significaron to do un orden de recompensas necesariamente convenidas con las tropas para procurar la adhesión y la fidelidad. Tras el cierre se ese ciclo la situación de guerra persistió hasta la década de 1870, en forma de guerra externa, guerra interprovincial y guerra entre facciones.

En virtud de nuestros propósitos, una manera de constatar la experiencia militar de la Puna en la etapa post-independentista es mediante el seguimiento de los registros de las fuerzas alistadas en el territorio, así como las instancias de movilización. Hemos logrado reconstruir la composición numérica de las tropas según el detalle del Cuadro 1, para cinco décadas sucesivas, entre 1820 y 1860.

\begin{tabular}{|c|c|c|c|c|c|c|c|}
\hline Lugares/Años & $\mathbf{1 8 2 6}$ & $\mathbf{1 8 3 1}$ & $\mathbf{1 8 3 4} \mathrm{A}$ & $\mathbf{1 8 3 4} \mathrm{B}$ & $\mathbf{1 8 3 6}$ & $\mathbf{1 8 3 7}$ & $\mathbf{1 8 6 7}$ \\
\hline Yavi & 20 & 110 & 102 & 117 & 225 & 76 & 351 \\
\hline Rinconada & & & & & 243 & 66 & 285 \\
\hline Cochinoca & & 152 & & 50 & 211 & 41 & 560 \\
\hline Santa Catalina & & & & & 117 & 50 & \\
\hline Varios & 91 & 82 & 109 & & & 56 & \\
\hline Total Puna & 111 & 344 & 211 & 167 & 796 & 289 & 1196 \\
\hline Total Jujuy & 973 & 1067 & 1675 & 1330 & 1612 & 883 & 4176 \\
& $100 \%$ & $100 \%$ & $100 \%$ & $100 \%$ & $100 \%$ & $100 \%$ & $100 \%$ \\
\hline Relación Puna/ Jujuy \% & 11,4 & 32,2 & 12,5 & 12,5 & 49,3 & 32,7 & 28,6 \\
\hline
\end{tabular}

Cuadro 1. Provincia de Jujuy. Empadronamientos y/o acuartelamientos de las milicias en los departamento de la Puna, 1826- 1868 ( $\mathrm{N}^{\circ}$ absoluto de personas). Fuente: elaboración propia sobre la base de Pie de lista, alistamientos y/o enrolamientos de milicia y Guardia Nacional ${ }^{20}$.

19 Mata de López, Sara, “Guerra, Militarización ..."; Paz, Gustavo, “Reordenando la campaña: la restauración del orden en Salta y Jujuy, 1822-1825", en Fradkin, Raúl, ed., ¿Y el pueblo dónde está? Contribuciones para una historia popular de la revolución de independencia en el Río de la Plata, Prometeo, Buenos Aires, 2008, 209-222.

20 Paz, Gustavo, "El orden es el desorden". Guerra y movilización campesina en la campaña de Jujuy. 1815-1821", Plataforma del Programa Interuniversitario de Historia Política, $\mathrm{N}^{\circ} \quad 7, \quad 2010$, http://www.historiapolitica.com/dossiers/lasguerras/ (Consultado el 20/05/2019); escuadrones de milicia de la campaña de Jujuy, sin fecha. Archivo Histórico de Jujuy (en adelante AHJ). Caja Documento, año 1826. Regimiento 
En una primera etapa, cuando finaliza la Guerra de Independencia y hasta los años 50 del siglo XIX, el ordenamiento del ejército se hizo bajo la órbita de los Estados provinciales que emergieron luego de caída del poder central del Directorio del Río de La Plata, en 1820. Esos 'brazos armados' de las nuevas entidades autónomas y soberanas se reclutaron en la ciudad y la campaña incluyendo en sus filas a todos los varones nacidos y domiciliados en cada provincia, 'mayores de edad', y constituyeron cuerpos de funcionamiento regular. A partir de entonces, de manera periódica, se levantaban listas de los agentes afectados al servicio, varones mayores de 16 años, según su residencia. A cada jurisdicción departamental correspondía un determinado cuerpo y jefatura. Como en otras provincias de la Argentina, en nuestro caso, las fuerzas de las zonas rurales jujeñas eran de funcionamiento regular, estaban al mando de un comandante departamental, designado por el gobernador y el enrolamiento en la milicia se hacía en plenitud de los derechos civiles; por lo tanto, estas huestes no se conformaron por voluntarios, ni por 'vagos', reunidos en leva u otras formas de reclutamiento forzado ${ }^{21}$. En el caso de Jujuy, inicialmente, por su carácter de ciudad subalterna de la Intendencia de Salta las directrices para su organización procedían de aquella ciudad; luego de lograr la independencia en 1834 recién fue prerrogativa propia. Hemos registrado esos empadronamientos en la Puna, consignados en el Cuadro 1, para los años 1826, 1831, 1834 y 183622. Por otra parte,

de Lancero Cívico del 18 de marzo de 1831, 4 y 6 de mayo de 1831, 19 de junio y 12 de julio de1831, Jujuy; Escuadrón de la Quebrada de Humahuaca del 24 y 29 de Mayo de 1831, Iruya, 5 y 27 de junio de 1831, Humahuaca; Regimiento de Caballería de la Puna del 13 de junio de 1831. AHJ. Caja Documentos, año 1831. Ayudantía del Gobierno de Jujuy del 20 de abril de 1834, Jujuy; Escuadrón de Tiradores de la Puna del 16 y 17 de febrero de 1834, Cochinoca y Yavi. AHJ. Caja Documentos, año 1834 A. Estado Mayor General, Ejército de Jujuy auxiliar de Salta del 30 de diciembre de 1834, Jujuy. AHJ. Caja Documento, año 1834 B. Batallón de Cazadores del 18 de agosto de1836, Jujuy; Regimiento 3, General Belgrano de la Quebrada de Humahuaca del 30 de noviembre de 1836, Huacalera, Tilcara y Humahuaca; 28 de noviembre, Caspalá y Valle Grande; Regimiento 1 de Federados del 6 y 12 de diciembre, Perico, 18 de diciembre de 1836, Palpalá, 11 de diciembre, Monterrico; Batallón de Cazadores del 18 de agosto y 9 de noviembre de 1836, Jujuy y alrededores; Regimiento 4 Gral. Heredia del 16 de diciembre de 1836, San Lorenzo; Regimiento 5 Gral. Rosas del 13 de septiembre, Cochinoca y del 19 de septiembre, Yavi; Batallón de Infantería Gral. Dorrego del 11 y 13 de diciembre de 1836, Rinconada y del 26 de noviembre de 1836, Santa Catalina. AHJ. Caja Documento, año 1836. Listas de los distintos cuerpos de la milicia de la provincia acuartelada en Jujuy, 10,14, 15 y 16 de julio de 1837, Jujuy. AHJ- Caja Documentos, año 1837. Enrolamiento de la Guardia Nacional de Jujuy. AHJ. Caja Documento, año 1867.

21 Macías, Flavia, "Introducción al dossier Las milicias en acción. Revoluciones, elecciones y ejército en la Argentina de la segunda mitad del siglo XIX", Plataforma del Programa Interuniversitario de Historia Política, N 17, 2011, http://www.historiapolitica.com/dossiers/dossiermilicias/ (Consultado el 14/09/2019).

22 En todos estos casos las listas registran a los habitantes, residentes en ese año, en cada uno de los partidos de la Puna, de manera que se trata de fuerzas que corresponden a los pobladores de la región, siguiendo el criterio de domicilio para su alistamiento, como se explicó anteriormente. La nómina de 1826 se titula "Relación del Número de tropas extraídas de los escuadrones y milicias de la campaña de Jujuy, con expresión del partido al que pertenecen", la misma indica cada partido; el escuadrón de Yavi, Iruya, Humahuaca y Tilcara contiene el nombre de cada miliciano, mientras el de Santa Victoria establece además el estado civil y la cantidad de hijos de cada uno. Por su parte, el Gobernador Delegado de la Provincia de Salta estableció un nuevo arreglo de toda la milicia en 1831 por el que formuló escuadrones de 150 a 250 agentes, constituyó los cuadros de la plana mayor, decretó el pase de 
esas fuerzas regulares eran movilizadas en determinadas circunstancias de amenazas de guerras o ante efectivas contiendas. De esas instancias hemos tomado nota en la documentación en dos ocasiones para las tropas de la Puna, lo que implicó el traslado de ellas y su reunión en la Ciudad de Jujuy, sucesos que figura como acuartelamientos y corresponden a los datos de 1834 B y en 1837 del Cuadro 123.

A partir de mediados del siglo XIX, con la sanción de la Constitución Nacional de 1853, a la par de la constitución de los poderes del flamante Estado argentino y en reemplazo de los ejércitos provinciales, surgió una nueva entidad militar 'nacional' presente en toda su jurisdicción, aunque manteniendo por un tiempo la injerencia de los gobiernos provinciales en su armado y funcionamiento: la Guardia Nacional24. Por ley nacional del 5 de junio de 1865 se declaró obligatorio el enrolamiento en la Guardia Nacional activa de la República para todo ciudadano argentino. También se sostuvo un criterio domiciliario para efectivizar el registro de los distintos cuerpos

revista de altas y bajas cada dos meses, entre otras normativas. Es por estas disposiciones que las fuerzas de la Puna quedaron formadas entonces por el 'Regimiento de Caballería de la Puna' en el que se alistaron, indicando nombre y rango de cada uno, dos escuadrones, uno de Cochinoca con dos compañías y otros de Yavi y Santa Victoria, así como los integrantes de la plana mayor. Algunos de los que aparecen en esa nómina figuran desempeñando distintos cargos como el Cacique de la Rinconada Tiburcio Guanuco y el cacique de Casabindo Francisco Chocovar, el alcalde del partido Tomas Quispe (Correspondencia de los 'Caciques Gobernadores de los cuatro curatos de la Puna y sus respectivas comunidades' del 1 de diciembre de 1826, Rinconada, Archivo Histórico de Salta (en adelante AHS), Fondo de Gobierno, Caja 71, carpeta 2C). Siguiendo las mismas normativas de periódicos pases de revistas, entre los meses de febrero y abril de 1834 se reportó a Salta desde la dependencia de Jujuy, un cuadro -en este caso no es un listado nominativo- de las fuerzas efectivas, del número de hombres y armamentos del Primer Escuadrón de Tiradores de la Puna, con asiento en Yavi y del Primer Escuadrón de Flanquedores de la Puna, emitido en Cochinoca. Repitiendo ese diseño, en el mismo año, en una tabla con cantidades de los agentes según los distintos rangos y del armamento, se resume el estado general de las milicias correspondientes a la 'Ayudantía del Gobierno de Jujuy', clasificadas en nueve escuadrones, donde se incluye los pertenecientes a la Puna. Finalmente, en 1836 se hizo el primero y más completo relevamiento de la composición del cuerpo de defensa de la provincia de Jujuy, ya en su etapa autonómica. También se trata de las matriculaciones nominativas de cada departamento, con distinto grado de desagregación de los datos. Así, mientras el Regimiento 5, General Rosas, con dos compañías correspondientes a Yavi y dos a Cochinoca, se limita a poner la jerarquía militar y el nombre de cada individuo que se presentó al llamado de enrolamiento, en cambio, el Batallón de Cazadores Gran Dorrego (con sus tres compañías de Rinconada y de Santa Catalina) incluye referencias sobre las edades, profesiones, lugar de residencia departamental y estado civil de todos los sujetos (listas correspondientes a cuerpos de otros lugares de la provincia suman el dato de la 'patria' de origen que muchas veces es distinta a la residencia).

23 En el cuadro 1, la información sobre el año 1834 con la letra B remite al ejército formado por los defensores de la autonomía jujeña de la provincia de Salta, en noviembre de 1834. El proceso implicó un enfrentamiento bélico entre las fuerzas del ejército regular de Salta y una tropa fiel a los autonomistas. Una vez finalizado el conflicto, en diciembre de ese año se rastrearon y anotaron en un extracto cuantitativo las fuerzas que participaron, sus respectivos números y los sueldos según las jerarquías militares, el que incluye dos agrupaciones trasladadas desde Yavi y Cochinoca. El segundo acuartelamiento se trata de una movilización general en resguardo de la seguridad de la ciudad y adiestramientos de las tropas durante la Guerra de la Confederación Peruano-Boliviana, del año 1837. Ante lo inminente de esa guerra el Gobernador de Jujuy, Pablo Alemán, decretó un acuartelamiento general de toda la tropa en la ciudad de Jujuy en coincidencia con la fecha cívica del 9 de julio de ese año. La reunión de las fuerzas duró, por lo menos, hasta mediados del mes de agosto. Para esos dos meses contamos con listas de los acuartelados del Batallón Gral. Dorrego y del Regimiento Gral. Rosas, sus nombres, edad, estado civil, profesión, residencia en los parajes de los departamentos de la Puna y 'patria' de origen.

24 Macías, Flavia, "Introducción al dossier...". 
militares. El primero que se pudo concretar en la Puna data de 1867, el mismo que plasmamos en el Cuadro 1.

Hasta la década de 1830 el 'partido' de la Puna comprendía los curatos de Rinconada, Yavi, Casabindo, Cochinoca y Santa Catalina (Ver mapa 1). Entonces alcanzaba un área mayor que la de los actuales límites provinciales ${ }^{25}$, pues incluía en su órbita política-administrativa la localidad de Santa Victoria, y en el curato de Humahuaca a Iruya, actualmente pertenecientes a Salta. Pero, además, estos dos parajes eran parte de las propiedades del Marquesado de Tojo, con haciendas en los departamentos de Cochinoca, Yavi y Santa Catalina y Tarija en Bolivia ${ }^{26}$.

Incluyendo esos distritos, el empadronamiento de 1826 incluido marca el nivel más bajo de toda la serie construida, con 111 efectivos en total. Esa cifra representa el $11 \%$ de toda la fuerza alistada ese año en la jurisdicción de Jujuy. Efectivamente, por los datos que aporta Paz, seis distritos del área de las 'tierras bajas' jujeñas reportaron 811 milicianos, es decir, un $83 \%$ del total27. Este mismo autor afirma que para entonces se llevaba a cabo una política de desmilitarización desde el gobierno de Salta, procurando reducir el número de soldados. Sabemos que la década de 1820 se presenta en las tierras altas con uno de los valores demográficos más bajos desde la creación del virreinato del Río de La Plata, pero era todavía la región de mayor concentración de población de Jujuy.

25 Jurídicamente el departamento de Susques, que aparece en el mapa, fue parte de la provincia de Jujuy recién desde 1943. Tras un largo litigio por el control de la zona entre Bolivia, Chile y Argentina, en 1900 parte de este territorio en conflicto pasó a la soberanía de la Argentina como el Territorio Nacional de los Andes, cuya administración y gobierno dependía del Estado nacional. Recién en 1943 se crearon cuatro departamentos con dependencia de las provincias de Jujuy, de Salta y de Catamarca, quedando Suques para la primera (Delgado, Fanny, "La ciudadanía en el sector norte del Territorio Nacional de los Andes (Susques), perspectiva indígena- perspectiva estatal", en Plataforma del Programa Interuniversitario de Historia Política, $\mathrm{N}^{\circ}$ 6, 2010, http://www.historiapolitica.com/dossiers/territorios/ (Consultado el 21/01/2021).

26 Se trata del voluminoso patrimonio territorial, al que aludiremos varias veces en este documento, de un poderoso actor local; el marqués de Yavi, Fernando Campero. Todo el conjunto constituía una gran empresa familiar de origen colonial fundada institucionalmente en las mercedes de tierra, la encomienda, el mayorazgo y los títulos nobiliarios. Madrazo, Guillermo, Hacienda y encomienda en los Andes. La Puna de Jujuy bajo el marquesado de Tojo, siglos XVIIXIX, Fondo Editorial, Buenos Aires, 1982.

27 Paz, Gustavo, "El orden es el desorden....". 


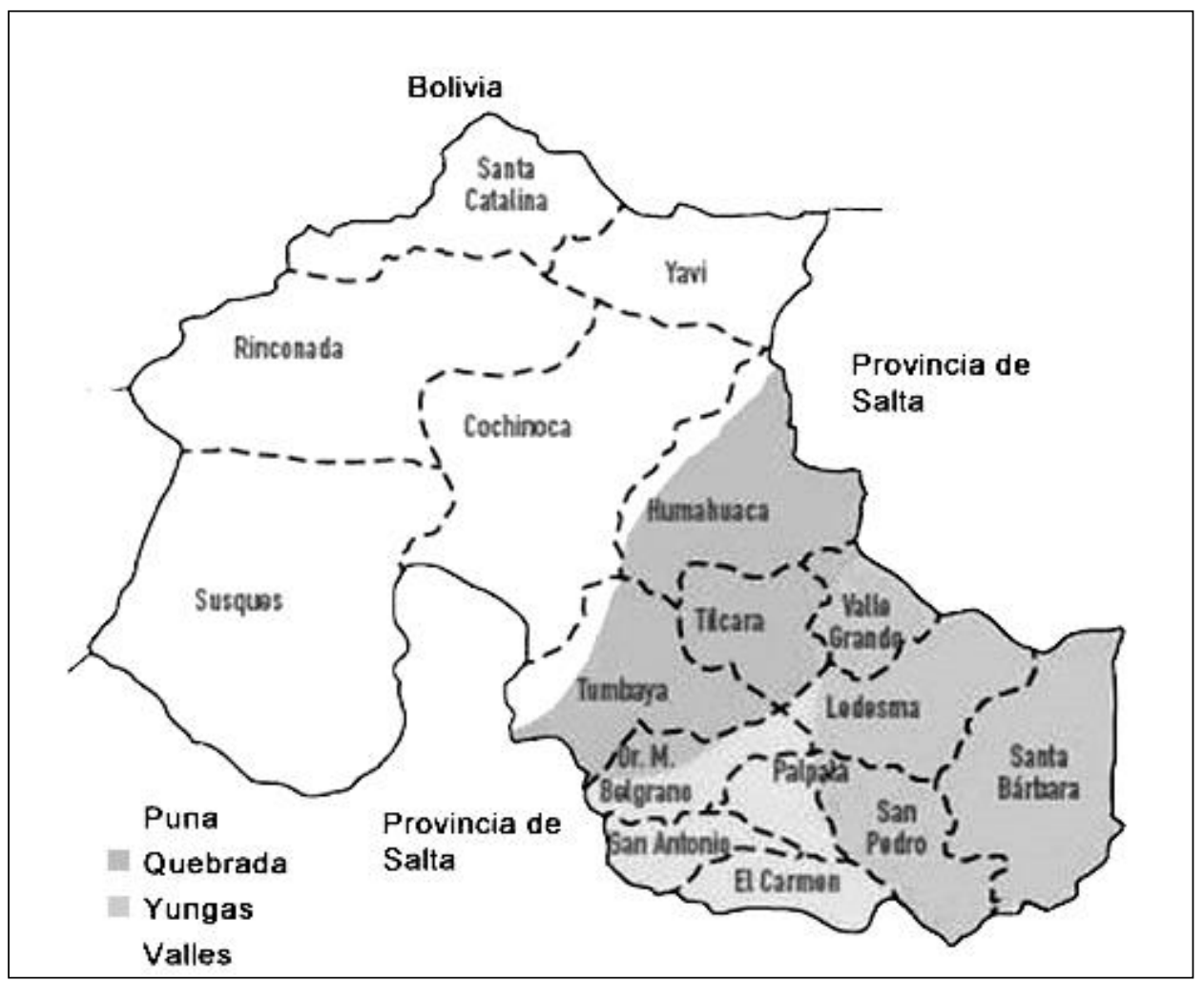

Mapa 1. Jujuy, regiones geográficas. Fuente: El Tribuno, Jujuy, 19 de abril de 2016, Laura Ballatore, https://www.eltribuno.com/jujuy/nota/2016-4-19-1-3-0-presencia-en-las-cuatro-regiones-de-la-provincia (Consultado el día 10 de agosto de 2020).

A continuación, para analizar los datos del Cuadro 1 secuenciamos en tiempo en distintas etapas y reconstruimos el comportamiento de las fuerzas militares de la Puna en el transcurso de cada una ellas. Así damos cuenta de los sucesos en que los milicianos de esta región se vieron involucrados en acciones de naturaleza castrense.

\section{El conflicto entre la Liga del Interior y la Liga del Litoral (1830-1840)}

Como se desprende del gráfico analizado, en 1831 las fuerzas nucleadas en un Regimiento de Caballería de la Puna muestran crecimiento respecto de 1826. Se contabilizaron 344 agentes, lo que significó un $32 \%$ de la milicia reglada en la jurisdicción de Jujuy. Este alistamiento fue parte del reordenamiento que llevó a cabo el gobierno de turno, gravitando una mayor beligerancia. Efectivamente, la situación de guerra se reactivó entonces por el enfrentamiento del bloque de provincias agrupadas en la Liga del Interior, de bandera unitaria, y las que se congregaron en torno a la figura de Buenos Aires y su gobernador Juan Manuel de Rosas en la Liga del 
Litoral, de tinte Federal. Jujuy y Salta se alinearon al bando unitario de la Liga del Interior, nucleada alrededor de José María Paz en 1830. En este contexto, las fuerzas de la Puna fueron movilizadas ese año para "defensa del punto de San Antonio" 28 y, lvego, para sofocar un amotinamiento de las tropas de Iruya y Valle Grande 29.

La normativa de regularización de la milicia local alcanzó a todos los 'habitantes' (sin ninguna otra atribución) entre 16 y 50 años, procedimiento que perduró como pauta de alistamiento hasta la reglamentación de la Guardia Nacional, a mitad del siglo XIX. Ella impuso la portación de papeletas de enrolamiento y la obligación de aviso de salidas del vecindario al conjunto de los milicianos ${ }^{30}$. La reglamentación ad hoc instauró, como en otras regiones del Río de La Plata, el sistema de asambleas para impartir el disciplinamiento de las tropas, siguiendo la forma de reuniones semanales doctrinales, fijadas para los días domingos ${ }^{31}$. Sin embargo, en la Puna la frecuencia dominical establecida resultaba inviable por la geografía montañosa y las distancias que debían recorrerse, por lo tanto, se hacía coincidir los ejercicios doctrinales con la celebración de las fiestas patronales ${ }^{32}$.

Para reclutar soldados el gobierno salto-jujeño actuante de la Liga Unitaria alentó la reposición de anteriores mecanismos de incentivos, como la recompensa de la eximición del pago de arriendos a los milicianos en servicio activo y el goce del fuero militar33. El libramiento de las obligaciones de arriendo duraría hasta un año después de terminada la guerra y los propietarios que violaran la norma podían percibir multas, aunque se preveía una indemnización de esas rentas cegadas con desembolsos a futuro de fondos públicos.

Por la disposición de 1831 en la Puna lograron armarse dos escuadrones en los curatos de Yavi y de Cochinoca, mientras que en Santa Catalina y Rinconada la falta

28 Localidad al sur de Jujuy, $32 \mathrm{~km}$ distante de la ciudad capital, sitio de tránsito del camino carretero que unía a la ciudad de Salta y sede de la Receptoría de la Aduana de Jujuy -conocida como La Cabaña (Conti, "De las Guerras de la Independencia...", 89).

29 Correspondencia oficial del Gobernador Fermín de la Quintana del 25 de junio de 1831, Jujuy. AHJ. Caja Documentos, año 1831.

30 Decreto gubernativo del 12 de abril de 1831, Salta. AHJ. Caja Documento, año 1831

31 Correspondencia del Gobernador de Salta al Teniente Gobernador de Jujuy del 16 de abril de 1831, Salta. AHJ. Caja Documento, año 1831.

32 Correspondencia oficial sobre el arreglo de regimientos de Iruya y de Santa Victoria del 5 de junio de 1831, Humahuaca. AHJ. Caja Documento, año 1831.

33 Decreto gubernativo del 7 de octubre de 1831, Salta. AHJ. Caja Documento, año 1831. 
de caballería impedía el arreglo militar, el que solo era factible de lograr con la formación de un batallón de infantería, por ser todos "gente de a pie"34.

El cambio de gobierno que impuso la derrota de la Liga Unitaria en noviembre de 1831 generó un contexto incierto para el bando federal que ocupó el gobierno local a fines de ese año. En paralelo a las circunstancias que imperaban por el peso de las reparaciones de guerra exigidas por el líder federal Facundo Quiroga ${ }^{35}$ y el peligro de acometida de los emigrados políticos a Bolivia36, la cuestión militar estuvo a la orden del día. Pese a las urgencias del momento, la institucionalidad militar acusó cierta inconsistencia en la región, según lo expresaban las misivas procedentes de Salta, las que advertían de la demora para proceder al arreglo de las milicias de todos los departamentos de Jujuy y el desconocimiento del número de ciudadanos disponibles para conformar las tropas ${ }^{37}$. Por la lectura entre líneas de la correspondencia cursada en 1832 se descubre una situación generalizada de repulsa a la milicia, de 'traición' en los planteles de la oficialidad y de recelo entre ellos, así como una fuerte acometida de los propietarios para recuperar las rentas de sus arriendos denegados en la etapa unitaria.

El hecho de que no se pudieran concretar los alistamientos exigidos desde Salta obedeció, entre otros factores, a grandes ausencias de los pobladores de las tierras altas porque habían partido a los viajes de intercambio de granos y trasladado en forma temporaria a las zonas de valles para la siembra38. Pero, también, había un generalizado rechazo al reclutamiento luego que la vorágine de los sucesos bélicos desatados en un corto plazo, por la lucha entre unitarios y federales entre 1830 y 1832 ,

34 Correspondencia oficial del Subdelegado de la Puna del 13 de junio de 1831, Cochinoca. AHJ. Caja Documento, año 1831.

35 El tratado de reparaciones exigido por Facundo Quiroga obligaba a las ciudades de Salta y de Jujuy a pagar 30.000 pesos en metálico, 14.500 cabezas de ganado vacuno, 2.000 caballos y 800 bueyes. La cobertura de esa deuda fue un punto de disrupción en el financiamiento de la guerra porque afectó, además de los tradicionales sectores comerciantes y ganaderos de la ciudad de Jujuy, a actores singulares de fuerte peso (como las rentas de arriendo del Marqués de Tojo, los fondos de las fincas capellánicas y los ingresos de los 'curas de la Puna') y obligó a la actuación de fuerzas militares locales en el desenlace de los acontecimientos.

36 La expulsión de todos los ciudadanos que habían participado del régimen derrocado ocasionó una corriente de emigrados políticos que se asentaron en Bolivia, inaugurando un foco de permanente tensión en la zona fronteriza (Conti, "De las Guerras de la Independencia..."). La situación se plasmó en distintas operaciones lideradas por este grupo para desestabilizar los mezquinos resortes norteños del régimen federal rosista. Nos interesa destacar que en cada una de estas instancias hubo intervención de las distintas fuerzas castrenses organizadas, con participación directa de las milicias de la Puna.

37 Comunicación oficial del 15 de junio de 1832, AHS. Libro Copiadores de Gobierno, N²12, años 1831 a 1833.

38 Esto fue un motivo real de incumplimiento de los enrolamientos, quizás también utilizado como excusa, frecuente en toda la etapa de análisis. De hecho, los habitantes de las tierras altas jujeñas se movían en forma constante y en distintos períodos para completar la subsistencia de la familia, ya sea para intercambiar productos en las numerosas ferias realizadas o para acceder a pisos ecológicos distintos para el cultivo y pastaje de los animales. 
hiciera patente los perjuicios ocasionados frente al cumplimiento del servicio de $\operatorname{armas}^{39}$.

El final del dominio unitario también reportó un relevo de las autoridades locales y del mando de los distintos cuerpos militares. Respecto al nombramiento de la plana mayor de cada destacamento, el decreto que había ordenado el ejército de Salta y Jujuy en 1831 solo establecía que las vacancias de oficiales debían ser cubiertas por las propuestas que adjuntaran los respectivos jefes. Hemos visto que esa actuación era responsabilidad del Subdelegado de la Puna en esta región40, quien elevaba las listas con los nombres escogidos. Según sus apreciaciones, muchas veces, era difícil completar una planilla con sujetos idóneos, 'patrióticos', leales. En la selección contaba el haber servido en la Guerra de Independencia como uno de los antecedentes más preciados y, al parecer, en la Puna esa condición era extraordinaria. Además, los organizadores de esos cuadros superiores expresaban como dilemas el componente étnico de la población, según subraya esta misiva:

"Esos sujetos "no merecía haberlos colocado en la graduación en que se hallan distinguido por ser hombres de quienes el gobierno debe desconfiar [...] han sido los primeros que han franqueado a la sedición [...] y que en adelante no dejarán de presentarse cuantas ocasiones se les invite no obstante que en el presente manifiesten adhesión y fidelidad al gobierno, política o hipocresía propia del indio (subrayado nuestro) que oculta su veneno hasta lograr ocasión de manifestarlo"4l.

Asimismo, los oficiales de la Puna se vieron envueltos recurrentemente en confusos episodios de complicidad con las fuerzas y los hombres a quienes debían combatir, perseguir, apresar, lo que también generaba constantes remociones. Finalmente, como la guerra levantada por los representantes de la Liga Unitaria había terminado, en principio, debía caducar el decreto de eximición de los arriendos del

39 AHJ. Caja Documento, año 1832. Cochinoca, 24 de diciembre de 1832, correspondencia oficial del Comandante del Escuadrón.

40 La autoridad del subdelegado de la Puna, con amplias facultades de gobierno, justicia y policía, fue creada por una ordenanza del Rey de 1782, en el marco de las reformas Borbónicas de la monarquía española. Esta figura política subsistió en la etapa republicana, hasta 1852 (Fandos, Cecilia, "Viva la Santa Federación, mueran los salvajes unitarios'. El régimen rosista, los subdelegados y el gobierno de la Puna jujeña en la década de 1840", en Gutiérrez, Mirta y Citterio, Diego, comp., Historias breves de Jujuy II. Actores y prácticas de poder en los siglos XIX y XX, Cuadernos del Duende, San Salvador de Jujuy, 2019, 67-75).

41 Correspondencia oficial del 31 de marzo de 1834, Santa Catalina. AHS. Fondo de Gobierno, Caja 125, Carpeta, 1, año, 1834. 
año anterior. Imperando una 'confusión' de interpretación de la letra escrita de este decreto siguieron los reclamos tanto de arrendatarios como de propietarios. En cierto modo, el Subdelegado de la Puna dispuso una salida conciliadora que aseguraba los derechos de los arrenderos, eximiéndolos del pago, solo para aquellos que habían concurrido a la 'pacificación de Iruya', de cuya documentación probatoria del servicio podía contar de manera fehaciente el gobierno ${ }^{42}$. Del lado de los propietarios, el sujeto mayormente afectado, Fernando Campero, adscribió positivamente a esta vía de solución, tomando razón del listado de los dispensados por su participación en Iruya, porque de esa manera quedaban librado del pago una minoría de los arrendatarios $y$, también, porque así reaseguraba su derecho a reclamar al Estado la indemnización correspondiente, al entender que "[...] éste y no un particular es quien debe pagar o premiar los servicios que le prestan los ciudadanos"43. Más allá de este caso puntual, el resto de los propietarios endurecieron los mecanismos del cobro de la renta, visitando sus estancias personalmente y cargando con deudas de dos o más años a los arrendatarios ${ }^{44}$.

\section{La lucha por la autonomía política de Jujuy (1834)}

Retomando el Cuadro 1, en 1834, en el último estado general de la fuerza militar de Jujuy levantado bajo dependencia de Salta, la tropa de la Puna ligeramente volvió a descender en términos absolutos (211 agentes) y relativos a toda la jurisdicción (12,5\% del total). Luego, para finales de ese año hubo un nuevo reconocimiento de tropas en Yavi y Cochinoca durante el operativo de movilización general para luchar contra el gobierno de Salta por la autonomía de Jujuy. Las milicias de la Puna representaron en esa contienda una fuerza relativa del $12,5 \%$ del total

42 Correspondencia oficial del Subdelegado de la Puna del 17 de enero de 1832, Rinconada. AHJ. Caja Documento, año 1832. Se trataba solamente de 31 agentes que por concurrir a esa movilización habían servido activamente, mientras el resto, por su negativa de asistir en el citado servicio, encuadraban en la categoría de desertores y, por lo tanto, quedaban privados de esa recompensa.

43 Correspondencia de Manuel Anzoástegui (pariente y administrador de las fincas de Fernando Campero) al Subdelegado de la Puna del 15 de mayo de 1832, Tojo. AHJ, Caja Documento, año 1832.

44 Comunicación oficial del comandante de la zona del 21 de diciembre de 1832, Valle Grande. AHJ, Caja Documento, año 1832. 
provincial. La marcha de este conflicto hizo que esas tropas tuvieron que 'bajar' al escenario de guerra librado en los valles del sur, lindantes a Salta ${ }^{45}$.

Más allá de la cifra hay que considerar que la Puna se pronunció activamente a favor de la autonomía porque básicamente esa fue la decisión del poderoso Fernando Campero; en ese sentido expuso el comandante de Yavi que "La puna está decidida y mucho más si usted la llama [...] porque Don Fernando, que es quien nos proporciona todos los auxilios es el primer decidido"46. Así, la formación de una 'liga de la independencia' fue producto de una cuidadosa operación por la que el célebre hacendado de la Puna aportó para la causa dinero, armas y el arreglo de las milicias conformadas por sus arrendatarios. Aunque carecemos de testimonios directos sobre las ventajas que reportaba la independencia de Jujuy al Marqués, la conexión de algunos hechos nos permite enunciar alguna explicación. Lo cierto es que el territorio puneño no estaba plenamente asegurado para quedar integrado a la jurisdicción jujeña ya que se temía "una maniobra desde Salta" para mantenerlo bajo su soberanía. En consecuencia, se nombró inmediatamente como Subdelegado de la Puna (usualmente esa designación se hacía en Salta) a Luis Paredes para que "obre de acuerdo, en virtud de la combinación [...] con el Coronel Fernando Campero, Don Fermín de La Quintana, el comandante Ontiveros y demás jefes que se hallan en la Liga de la Independencia" 47.

Como trasfondo del asunto es preciso destacar que Campero venía sosteniendo una disputa con las autoridades de Salta por los arriendos embargados de la casa de Yavi. Esta tensión persistente y el efugio que reportó el apoyo a la facción autonomista tuvieron diversas derivaciones sociopolíticas y militares. Para su comprensión, narremos uno a uno los acontecimientos. Efectivamente, por disposición del gobierno salteño, obrando un pleito entre Fernando Campero y su sobrino Pedro Nolazco Uriondo por la "posesión del Marquesado de Yavi", los arriendos de las haciendas en él comprendidas debían depositarse bajo control estatal y servir de garantía de la deuda contraída por los tratados de paz con Quiroga, de 1831. Desde entonces, por una serie de dilaciones hábilmente manejadas por

45 Para la conocida Batalla de Castañares (decisiva para la autonomía jujeña, 13 de diciembre de 1834) la división de los jujeños se componía de 1.000 hombres a caballo y de unos 200 infantes disciplinados que llegaron de la Puna (Comunicación oficial del 12 de diciembre de 1834, Jujuy. AHJ, Caja Documento, año 1834).

46 Correspondencia oficial del 25 de noviembre de 1834, Yavi. AHJ, Caja Documento, año 1834.

47 Correspondencia oficial del 28 de noviembre de 1834, Jujuy. AHJ. Caja Documento, año 1834. Correspondencia oficial del 28 de noviembre de 1834, Jujuy. 
agentes defensores de los intereses de Yavi, esos acopios públicos de las rentas no se hicieron efectivos ${ }^{48}$. Pero en 1834 el apremio de esa deuda llevó a que el gobernador de Salta, Pablo de La Torre, ordenara incautar 5.000 pesos de los productos de los arriendos del "Marques". Por este hecho, Campero respondió con una "invasión" a Yavi con hombres armados desde Bolivia el día 8 de julio de 1834, tomando por asalto la casa del subdelegado y retirando de su poder el referido monto de dinero recolectado49. El reputado suceso del "robo de los arriendos" además de generar movilización militar y conflicto diplomático causó un "completo estado de efervescencia" social50. Pese a la parquedad de las fuentes para traducirnos en detalle esa situación podemos presuponer que los hechos, tanto el embargo oficial como la respuesta del propietario de la hacienda de Yavi, capturaron la atención de una población donde más del $90 \%$ vivía bajo el régimen de arrendamiento, dentro de las fincas del "Marques". Tal vez, la misma situación creada sea explicativa del beneplácito de Campero para acoger el proyecto de cambio de jurisdicción y gobierno como el que prometía el bando independentista jujeño protagonista de la autonomía provincial.

A su vez, la incursión de la cuadrilla invasora mandada por Campero puso en el tapete del conflicto las tendencias anexionistas de Bolivia sobre la Puna. En la historiografía disponible se ha discutido la real existencia de ese plan y la complicidad habida del marqués de Yavi con él. Entre las visiones que cuestionan la preconcepción de ese programa, Pavoni interpreta la acción de Campero en el proceso de independencia provincial como una demostración de fuerzas para finiquitar la extracción de sus rentas, porque en el fondo la atención expansionista de Bolivia estaba puesta sobre el Perú51. En los relatos de época, sin embargo, algún rumor daba sentido a esta creencia, en tanto y en cuanto, Campero a los pocos días de haber incentivado desde Yavi la causa de la autonomía de Jujuy literalmente la abandonó, regresando a su residencia boliviana y dejando acéfala la organización miliciana que él había iniciado52. En el desenlace de ese conflicto, la eclética toma

48 Comunicaciones oficiales del 2 de febrero de 1832, Yavi; del 24 de mayo de 1832, Toxo; del 26 de junio de 1832, Rinconada. AHJ, Caja Documento, año 1832.

49 Correspondencia de Felipe Heredia a Juan Manuel de Rosas del 22 de diciembre de 1836, Salta. Archivo General de la Nación. (en adelante AGN). Sala X, División Nacional, Sección de Gobierno, Secretaría de Rosas.

50 Libros copiadores de gobierno, notas del 11 y 18 de julio de 1834, Jujuy. AHJ, Caja Documento, año 1834. Correspondencia oficial del 23 de diciembre de 1834, Salta. AHS. Fondo de Gobierno, año 1835, Caja No 139.

51 Pavoni, Norma, El Noroeste Argentino en la época de la Alejandro Heredia, Fundación Banco Comercial del Norte, Tucumán, Tomo 1, 1981, 138.

52 Correspondencia oficial del 13 de diciembre de 1834, Yavi. AHJ. Caja Documento, año 1834. 
de partido de Fernando Campero fue crucial y, a la vez, consecuente a su interés de asegurar sus posesiones y disfrute de la renta de los arriendos.

\section{En la Guerra de la Confederación Peruano-Boliviana (entre 1836 y 1837)}

Un momento clave de la configuración de la plataforma militar fue el año 1836 debido al desarrollo institucional seguido en la provincia, la vinculación de Jujuy a la órbita de poder de Alejandro Heredia (Gobernador de Tucumán) y Juan Manuel de Rosas y un conjunto de innovaciones introducidas desde lo táctico-militar durante el gobierno de Pablo Alemán. Efectivamente, en ese año se conformó el Protectorado que incluía las provincias de Tucumán, Salta Jujuy y Catamarca, sujetas al régimen rosista; con hegemonía de la primera y su gobernador Heredia. Éste podía intervenir en cada una de las demás partes constitutivas del Protectorado, realizar recaudaciones y formar ejércitos en caso de guerra, como garante del predominio federal en el Norte argentino.

Paralelamente, y a instancias del Mariscal Santa Cruz, Presidente de la República de Bolivia (1829-1839), que tomó por la fuerza la región sur de Perú, quedó conformada la Confederación Peruano-Boliviana (1836-1839). El hecho de que Santa Cruz estuviera concediendo franquicias aduaneras al comercio de ganado procedente de Salta, sumado a la real o incierta -pero sin duda gravitante- supuesta amenaza de segregación de la Puna por anexión a Bolivia, inquietaron al encargado de las relaciones exteriores de la Confederación Argentina, quien consideró la posibilidad de declararle la guerra. Hay que decir que Rosas midió esa salida no sólo como un mecanismo de equilibrio en las soberanías territoriales del sur de América, sino también como una forma de sostener la cohesión política hacia el interior de la propia Confederación Argentina53.

Otro factor incidió en que 1836 marcara una coyuntura de cambio respecto a la conformación militar de la provincia. En efecto, una nueva normativa introdujo clasificación distinta de la fuerza de la campaña, distinguida en caballería e infantería, a la vez que se uniformó cada uno de los batallones y regimientos con vestimenta diferenciada por colores y símbolos. Quedaron establecidos cinco

53 Schmit, Roberto, “Argentina en el mundo (1830-1880)", en Fradkin, Raúl y Garavaglia, Juan Carlos, coord., Argentina. La construcción Nacional, tomo 2, Mapfre, Madrid, 2012, 225-306. 
regimientos de los cuales el Número 5, Gral. Rosas, correspondía a los departamentos de Yavi y Cochinoca y sólo un Batallón de Infantería, el Gral. Dorrego, constituidos por soldados de los departamentos de Santa Catalina y Rinconada ${ }^{54}$. En la secuencia temporal que venimos analizando, antes de la constitución de la Guardia Nacional, este fue el momento en que el empadronamiento de los agentes de la Puna fue de mayor gravitación. El Cuadro 1 nos permite visualizar este dato. Así, la inscripción de 1836 aumentó más de tres veces el valor promedio de agentes de 1826-1834 (208 individuos reconocidos en la milicia) y llegó a componer la inédita proporción del 50\% de todo el ejército de Jujuy, con una fuerza de 796 soldados puneños.

De nuevo el instrumento de la suspensión de la recolección de los arriendos fue usado como método de atracción de la tropa, solo que ahora aparecía como un pedido completamente emanado desde las bases milicianas-campesinas de la Puna y trasmitido por los intermediarios políticos ${ }^{55}$.

Además, fueron reajustados los ejercicios doctrinales, así como perfeccionados los métodos de instrucción militar. Especialmente, la caballería debía 'ayornarse' mediante el conocimiento de los procedimientos contenidos en el 'cuaderno de maniobras' que circulaba, porque también era difícil asegurar el aprendizaje dada la condición analfabeta de la mayoría de la tropa56.

Reinando estas circunstancias, la Confederación Argentina declaró la guerra a la Confederación Peruano-Boliviana en mayo de 1837 y a partir de entonces se libró abiertamente en el escenario provincial y regional de la Puna. Los conteos de tropa del Cuadro 1 que hemos tomado corresponden a los operativos de movilización, lvego de declarada la guerra. Como ya señalamos, el compromiso bélico asumido obligó a la realización de un acuartelamiento general en la ciudad de Jujuy, de todo el ejército provincial, en resguardo de la seguridad de la Ciudad y el adiestramiento de las tropas, que permaneció activo cerca de dos meses. El gobernador Pablo Alemán dispuso el organigrama de los ejercicios y la 'academia'57 desde la mañana

54 Registro Oficial, Compilación de Leyes y decretos de la provincia de Jujuy. Desde 1853 hasta el de 1884, Tomo I, Tip. Libertad de José Petruzzelli, Jujuy, 1885, 45-48.

55 Comunicación oficial del 15 de agosto de 1836, Cochinoca. AHJ. Caja Documento, año 1836.

56 Comunicación oficial del 11 de octubre de 1834, Humahuaca. comunicación oficial. AHJ. Caja Documento, año 1836. Probablemente el material de lectura entregado era el Reglamento para el ejercicio y maniobras de la caballería, que la imprenta del estado de Buenos Aires publicó en 1834.

57 Al respecto, una descripción establece que se le enseñará "la obligación del soldado, la del centinela, las leyes penales" (Comunicación del Gobernador del 19 de julio de 1837, Jujuy. AHJ, Caja Documento, año 1837). 
hasta la retreta y de los racionamientos, ordenando la "disciplina, la moral y la economía"58. La llegada de los contingentes estaba prevista para la fiesta cívica del 9 de julio.

Ahora bien, teniendo presente la cuantía de regulación general de las milicias obradas en 1836, visualizadas en el Cuadro 1, vemos un notorio descenso en el año 1837 en el momento en que la fuerza efectiva total de la Puna concurrió a Jujuy para cumplimentar el acuartelamiento. Todo el ejército de la provincia se redujo en $45 \%$, siendo muy representativo de esa cifra la ausencia de la milicia procedente de la Puna (que estuvo censada con 796 agentes en 1836 y ahora solo se había enviado 289 a la ciudad).

Por los reiterados partes emitidos se advierte que el cuerpo de infantería del Regimiento Gral. Dorrego debía completar el número de 300 soldados para presentarse en la Ciudad, misión que resultó una tarea difícil para los encargados de la reunión y remisión. No obstante, el pico más alto de ese batallón puneño efectivamente acuartelado en Jujuy fue de 229 hombres, en julio de 183759. Como veremos en el siguiente apartado esa diferencia en los números de los empadronados de 1836 y acuartelados de 1837 se explica por el levantamiento del Regimiento Gral. Dorrego.

Las operaciones bélicas se sucedieron entre agosto de ese año y junio de 1838 (el estado de guerra se prolongó hasta abril de 1839), lapso durante el cual el territorio de la Puna fue ocupado -con distintos avances y retrocesos- por el ejército boliviano. La defensa de las fuerzas locales se apostó en la Quebrada de Humahuaca, región que aportó las partidas protagonistas de los enfrentamientos, aunque la milicia puneña siguió asentada en la Ciudad de Jujuy, con numerosas bajas, sirviendo como base de apoyo de las fuerzas de las que se valió el propio Alejandro Heredia al asumir personalmente el comando de la guerra. Efectivamente, con los remanentes de los soldados enviados desde julio y nuevos grupos reclutados se reorganizó la infantería

58 Correspondencia al General en Jefe del Ejército de la Confederación de julio y del 31 de julio de 1837, Jujuy. AHJ. Caja Documento, año 1837.

59 Pase de revista del Batallón de Infantería, Gral. Dorrego del 24 de julio de 1837, Jujuy. AHJ. Caja Documento, año 1837. 
denominada Cazadores de Las Leyes y Cazadores de los Llanos60, mientras la caballería se rebautizó como Regimiento de Restauradores a Caballo.

Tras esta experiencia de finales de los años 30 no volvieron a registrarse ordenamientos generales de milicias en el territorio de la Puna hasta la década de 1860, salvo por la presencia de pequeños piquetes que custodiaban la agitada y conflictiva frontera con Bolivia. Ahora, queda claro que la década de 1840 no implicó el cese de los conflictos ni de la presencia de guerra, y en consecuencia la desmilitarización de la Puna tuvo otra causa. En efecto, a partir de 1840 la población masculina apta para conscripción estuvo protegida por la Contribución Directa de la Puna que eximió del servicio militar a todos los que se ajustaron al pago de ese gravamen. Esa protección permaneció hasta los primeros años de 1850, caducando definitivamente a partir de la formación institucional del Estado argentino. Este asunto se analizará con mayores detalles en el apartado siguiente.

\section{La formación de la Guardia Nacional, década de 1860}

Desde el plano militar, el cambio de época que inauguró la segunda mitad del siglo XIX tuvo como hito la estructuración de un ejército de carácter nacional, siendo uno de los componentes claves la Guardia Nacional. La organización del plantel militar en la provincia, según la nueva normativa nacional que obligaba a todos los ciudadanos argentinos entre los 17 y 60 años a formar parte de esa fuerza, llegó con dos meses de demora y se ejecutó ordenando la presentación masiva de los afectados para el 11 de junio de 185461. Desde entonces la evidencia documental devela que fue un proceso donde confluyeron diversas controversias de poder y fuertes reticencias para su formación. Como consecuencia de la rivalidad de los jefes, se sucedieron permanentes reacomodos y cambios de jurisdicciones y mandos militares de los cuerpos de milicias que se fueron creando62. El comportamiento indisciplinado de las tropas no solo era moneda corriente en los partes diarios de las distintas jefaturas de las guarniciones, sino que también la desobediencia e insubordinación fueron atribuidos al aliento en toda la campaña de los "demagogos

\footnotetext{
60 Integrada por 93 milicianos de Yavi, 57 de Cochinoca, 58 de Santa Catalina y 25 de Rinconada. Batallón de Cazadores de los Llanos del 7 de agosto de 1837, Jujuy. AHJ. Caja Documento, año 1837.

61 Registro Oficial, Compilación de Leyes..., Tomo II, 13.

62 Registro Oficial, Compilación de Leyes..., Tomo II, 41.
} 
y enemigos" del gobierno63. En el territorio provincial la organización más tardía de la Guardia Nacional, frenada por este conjunto de factores, fue la de los destacamentos de los departamentos de la Puna. La población de la Puna prácticamente no concurría a las convocatorias de empadronamientos y, además, los batallones no lograban completarse por la práctica establecida en esta población de ausentarse "en sus diligencias particulares, y otros directamente fugitivos pasándose para Bolivia o Salta"64.

Efectivamente, mientras en toda la provincia los distintos cuadros se formaron en 1855, recién en el año 1867 se crearon cuatro batallones de la Guardia Nacional correspondientes a esta región ${ }^{65}$. En el proceso de enrolamiento surgieron discordancias sobre la confiabilidad de determinados nombres para ocupar los planteles superiores de estas fuerzas, por las muestras de comportamientos 'díscolos'. Aun así, el alcance del primer enrolamiento de la Guardia Nacional en la Puna fue bastante superior al promedio logrado en la década de 1830 en términos absolutos, Cuadro 1 (1196 soldados), aunque con menor peso de lo que reportó este procedimiento en todo Jujuy ( $29 \%$ del total provincial) ${ }^{66}$.

En el balance general, es posible advertir el ímpetu de la militarización de la Puna en el concierto del conflicto con Bolivia, incluso por la trascendencia que tuvo a nivel provincial la organización inicial de las tropas. De todos modos, en una y otra etapa, la de la milicia provincial y la de la Guardia Nacional, resulta apreciable la gravitación de la movilización militar efectuada en la Puna.

Finalmente, para estimar la proporción de los soldados de la Puna con la cantidad de habitantes de la región, hemos cotejado datos de los censos de 1839 y de 186967, considerando para ello a la población masculina apta para el servicio militar y los registros de milicias y guardias nacionales relevados en fechas cercanas. De ese análisis resulta que, en promedio, se alistaron 360 vecinos de la Puna en la década de 1830, la población apta para la milicia según el censo de 1837 (es decir, la masculina entre 16 y 50 años) suma 1.374 personas, de manera que esa relación

63 Registro Oficial, Compilación de Leyes..., Tomo II, 102-103.

64 Comunicación oficial del 5 de julio de 1867, Yavi. AHJ. Caja Documento, año 1867.

65 Registro Oficial, Compilación de Leyes..., Tomo II, 504-505.

66 El enrolamiento de la Guardia Nacional de 1867 no incluye el del departamento de Santa Catalina por no haberse hallado en las fuentes consultadas.

67 Padrón General de 1839, Santa Catalina, 18 de julio; Yavi, Rinconada y Cochinoca 27 de agosto. AHJ. Caja Documento, año 1839. Primer Censo de la República Argentina, año 1869. (1872). Buenos Aires, Imprenta El Porvenir, 574-575. 
soldados enrolados y población militarizada fue del $26,2 \%$. Si consideramos únicamente el año más representativo de esa década, 1836, resulta un 56\%. Siguiendo el mismo cálculo, la proporción de la población alistada en la Guardia Nacional en 1867 ( 1.196 individuos, menos el departamento de Santa Catalina) respecto del total de la población comprendida para el servicio militar en 1869 (2.544 varones entre 16 y 50 años) fue del $47 \%$.

\section{El levantamiento del Batallón Dorrego como origen de la negociación de la Contribución Directa}

En el mes de septiembre de 1840 los jefes políticos68 de los cuatros departamentos de la Puna recibieron la orden de remitir 25 hombres cada uno para cumplir con el servicio militar en la guarnición de la Ciudad de Jujuy durante dos meses 69 . Al unísono replicaron las dificultades para hacer efectiva la disposición por encontrase ausente los pobladores, por haberse escondido al enterarse de la misiva o, simplemente, porque se negaron ir a la Capital por "no ser soldados"70. Los pocos agentes que lograron juntarse tampoco llegaron a destino porque antes de arribar se habían fugado y/o amotinado. En el gesto de estos actos, según lo dejaron asentado, parecía imperar una clara consciencia de la implicancia de la prestación a la que eran citados. Ese entendimiento se fundaba en la memoria inmediata de estas gentes quienes, según el informante oficial, se hallaban "muy alucinados y escabrosos por el maltratamiento que recibieron en los años atrás, en tiempos del Gral. Aleman cuya comportación (sic) asido (sic) un escarmiento para estos"71. Se trataba de la reminiscencia de frescas experiencias formadoras de una 'tradición militar' en la

68 Los jefes políticos o jefes departamentales fueron creados en la década de 1830 en la provincia de Jujuy (1835 y 1839) para atender los asuntos gubernativos de cada pueblo cabecera de los departamentos de campaña. Entre 1839 y 1847 eran elegidos por asambleas de ciudadanos, luego y hasta 1855 fueron seleccionados por el poder ejecutivo de la provincia y/o por un cuerpo judicial (Fandos, Cecilia, "Viva la Santa Federación...")

69 Los indígenas encomendados de la Puna, de los pueblos de Casabindo y Cochinoca, contaban con el antecedente de haber servido a la mita de plaza, en la etapa colonial. Esta institución, desde finales del siglo XVI, consistía en el desplazamiento de un número determinado de tributarios de cada encomienda a la ciudad cabecera para sostener servicios de trabajo a particulares y/o en obras públicas. Como demuestran las investigaciones existentes su funcionamiento se vio entorpecido por la negativa para trasladarse a la ciudad de Jujuy, o por los levantamientos contra el sistema de los mitayos de la Puna (Sica, Gabriela, "Las otras mitas. Aproximaciones al estudio de la mita de plaza en la Jurisdicción de Jujuy, gobernación de Tucumán, siglo XVII", Anuarios de Estudios Americanos, 71, 1, 2014, 201-226).

70 Comunicación oficial del 19 de septiembre de 1840, Santa Catalina. AHJ. Caja Documento, año 1840

71 Comunicación oficial del 16 de septiembre de 1840, Yavi. AHJ. Caja Documento, año 1840. 
región ${ }^{72}$. A su vez, la negativa para concurrir al servicio al que fueron convocados propició el inicio de una negociación que tuvo como resultado el amparo legal por el que se eximió a este extenso vecindario del servicio de las armas, por más de 10 años. Hablamos de la Contribución Directa de la Puna (1840-1851), cuya vigencia explica la ausencia de alistamientos generales en este territorio durante toda la década de $1840^{73}$.

En cuanto a la gestación de la tradición militar, la revisión del asunto nos lleva a profundizar el desarrollo del amotinamiento del Batallón Dorrego y el levantamiento que comprometió toda la Puna en el año 1837. Recordemos que Pablo Alemán fue el gobernador de Jujuy impuesto por Alejandro Heredia entre 1836 y 1838. A la vez, hemos puntualizado ya en cifras cómo su gobierno coincide con la intensificación de la militarización de la Puna. Precisamente, en este contexto comenzó a idearse el mecanismo de una contribución a cambio de la eximición de las milicias y se construyó un discurso trasmisor del mensaje que señalaba que los indios de la Puna preferían "ser tributarios antes que soldados", en los siguientes términos:

"En contestación al oficio del 25 de junio pasado en que me pide lo instruya con respecto a los hombres que tiene este departamento y capaces de ser ocupado en el servicio de la provincia por su onradez (sic) patriotismo y demás cualidades [...] debo decir que en este partido de Yavi no se encuentra mas vecino capaz que don Fernando Arancibia [...] En el departamento de Cochinoca es donde abitan (sic) todos los oficiales que se le presentaron en Humahuaca, los que existen en sus distritos y ese distrito es el que tiene buena gente en clase de tropa, y en Yavi algo regular y capaces de ser milicianos. En todo el curato de Rinconada y Santa Catalina no tiene un solo hombre de caballo de su vecindario, y según estos informados, reusan (sic) fuertemente

72 En el sentido que formula Fradkin de "un conjunto de concepciones, normas, prácticas y experiencias forjadas en torno a la organización miliciana". Fradkin, Raúl, "Tradiciones militares coloniales. El Río de La Plata antes de la Revolución", en Heinz, F, comp., Experiências nacionais, temas transversais: subsídios para uma história comparada da América Latina, Editora Oikos, São Leopoldo, 2009, 74-126.

73 La temática ha sido tratada por los siguientes autores: Delgado, Fanny, "Ingresos Fiscales de la Provincia de Jujuy (1834-1852)", Data, №2, 1992, 105- 109. Bushnell, David, “La política indígena de Jujuy en época de Rosas", Revista de Historia del Derecho, N²5, 1997, 59-84. Gil Montero, Raquel, "Tierras y tributo en la Puna ...", 227-255. Fandos, Cecilia, "Bajar a servir en la Ciudad de Jujuy. Servicios ciudadanos y resistencia indígena en la temprana República (1840-1860), Estudios Sociales del NOA", N²2, 2019, 117-141. 
los indios, tener el carácter de soldados [...] se que propusieron ser tributarios antes que soldados, [...]"74.

El texto revela la emergencia de una proposición colectiva y distintiva de los actores directamente afectados. La maduración de ese concepto se liga al levantamiento que protagonizó unos meses después el Batallón Dorrego. Al respecto, la bibliografía anota que en julio de 1837 hubo primero una sublevación en la guarnición de Yavi, provocando la fuga de un grupo de rebeldes a Bolivia. Cuando las noticias del suceso se esparcieron, los milicianos de los puntos de San Juan y Granados, del departamento Rinconada, también se amotinaron y se pasaron a las tropas de Bolivia. Desde Jujuy se movilizó una partida para reducir la rebelión, que resultó rechazada por la acción de los rebeldes ${ }^{75}$.

Un repaso más atento a la forma en que se sucedieron estos hechos nos permite distinta interpretación del conflicto. En efecto, la convocatoria del acuartelamiento general en la Ciudad de Jujuy que mandó practicar Alemán en julio de 1837 y, a propósito de ella, el levantamiento del Batallón Dorrego el día 2 de julio de ese año, constituyen los hitos determinantes del conflicto que se venía gestando. En cuanto a lo primero, los preparativos de la remisión de 300 soldados de la Puna del cuerpo de infantería se planearon con un mes de anticipación a la reunión general de todo el ejército provincial previsto para el 9 de julio del año 37. Para el primero de julio todas las compañías puneñas debían concentrarse en el punto de Abra Pampa para iniciar la marcha hacia 'abajo', a la ciudad de Jujuy. En esos días preliminares ya corrían los rumores de sublevación de las tropas de Rinconada, circulaban noticias de reuniones con bolivianos y se reportaba, una y otra vez, la dificultad de concretar el número de gente que debía partir al cuartel citadino76. No obstante, un número cercano a los 280 agentes, de las fuerzas de caballería e infantería de la Puna, arribó y permaneció acuartelado en Jujuy por el término de dos meses y medio; redistribuyéndose luego sus hombres en los cuerpos de guerra creados por Alejandro Heredia (el Batallón de Cazadores Defensores de las Leyes y Cazadores de los Llanos) para enfrentar a la confederación Peruano-Boliviana desde septiembre de ese año.

74 Comunicación oficial del 28 de julio de 1836, Rinconada. AHJ, Caja Documento, año 1836.

75 Sánchez, Matías, Nación e Identidad..., 153; Paz, Gustavo, "Auge y caída del 'comunismo...", 96.

76 Correspondencia oficial del 4 y 26 de junio de 1837, Cochinoca. AHJ. Caja Documento, año 1837. 
En el transcurso se produjeron importantes bajas por enfermedades y, sobre todo, por deserciones masivas (cercanas al $50 \%$ de los efectivos) ${ }^{77}$.

Pero otros soldados nunca llegaron a destino porque no se presentaron durante el alistamiento y porque algunos, aún reclutados, los de la segunda compañía del Batallón Dorrego, se sublevaron78. Por los testimonios recogidos en los sumarios de averiguación de estos hechos se reconocen los intensos preparativos y deliberaciones, los detalles de las conexiones y tratativas en Bolivia y los motivos esenciales del movimiento. Efectivamente, en el pequeño pueblo de San Juan y Granados se concretaron varias reuniones, convocadas por el Alcalde del partido y otros sujetos encargados de correr la voz en cada punto de esa campaña, alegando que la propuesta de esa reunión fue "presentarse a Bolivia y no pertenecer a esta República". Así, concretaron al menos dos visitas protocolares con una comitiva integrada por los vecinos del pueblo, consensuada entre ellos, quienes sostuvieron primero una entrevista con el corregidor de "San Pablo"; por su encargo, hicieron lo propio con el Gobernador de Lipez en San Cristóbal, dirigiéndose también a Talina y Esmoraca79. Producto de esas conversaciones, recogieron la recomendación que "no obedecieran" a Bolivia y que, dirigiéndose al gobierno jujeño, "pidieran ser tributarios, y que no tomen parte en la milicia, y en el caso de no ser admitidos que se pasen a la República de Bolivia"80. En ese hilo argumental, una carta emitida por la esposa de uno de los líderes de la sublevación de San Juan y Granados, Teodora Coria, al comandante del Batallón Dorrego, José María Uriburu, asegura que no son gente "alzada", que "bajan" hacia la ciudad de Jujuy "muy en contra ellos" y que "hasta que Ud. no pongan la gente en los tributos no obedecemos"81.

La idea del pacto tributario que les recomendaron en Bolivia y la fuerte proclama de una condicional desobediencia fueron efectivas. En los hechos, desde entonces, mientras duró la guerra de Confederación Peruano-Boliviana y hasta que en 1840 volvió a sentirse la presión por el cumplimiento de servicios que exigían, una vez más, 'bajar' a la ciudad, no se alistó ni movilizó miliciano alguno de esta

77 Juicio a desertores del 12 de octubre de 1837, Jujuy. AHJ, Caja Documento, año 1837; Lista de desertores y amotinados de los Cazadores, Defensores de la Leyes, 1 de noviembre de 1837, Jujuy. AHJ, Caja Documento, año 1837.

78 Declaraciones de implicados del 14 de julio de 1837, Jujuy. AHJ, Caja documento, año 1837.

79 Se trata de puntos geográficos situados en la línea de frontera que distan entre 200 y 500 kilómetros de Rinconada.

80 Sumario de declaración de los sublevados de San Juan y Granadas, 8 de agosto de 1837, Cochinoca.AHJ. Caja Documento, año 1837.

81 Correspondencia oficial del 29de julio de 1837, Río San Juan. AHJ. Caja Documento, año 1837. 
jurisdicción, al punto expresado por un oficial de que "echar la mira en ellos es ya imposible"82. Por supuesto, en lo inmediato se aseguró una fuerte represalia de persecución y castigo, parte de amotinados del batallón Dorrego fueron apresados y remitidos a la Capital para integrar las filas de los militares en línea83, y se ordenó un éxodo general de la población y el ganado de la Puna, dejando en su defensa una fuerza de tres partidas, con sus oficiales expertos, apostadas una en Yavi, otra en La Quiaca y otra en Toquera, como mejor forma de evitar los "males que pueden crear las relaciones de amistad, familia comercio y otros" 84 .

Pero, pasada la emergencia de la guerra, fue considerada la propuesta de los puneños y, en consecuencia, las autoridades terminaron cediendo y concediendo el tributo de exclusión en las milicias. La agudización de la resistencia que desencadenó en la sanción de la memorable ley contributiva, en definitiva, fue a propósito de la exigencia a los ciudadanos de la Puna a servir en la Guardia del Principal. Es interesante acotar que con el nombre de 'Derecho Exención Personal' se reeditó ese tributo, aunque no de forma idéntica, en la década de 186085. Ambos instrumentos permitieron la eximición del servicio militar a cambio del pago de una contribución y nacieron como respuesta a la exigencia de la 'fatiga', por rotación y por turnos, de los milicianos de la provincia en la guarnición permanente que hacía la custodia y defensa de la ciudad capital -la Guarnición del Principal. El mecanismo puesto en funcionamiento en 1863 se hizo para una misma problemática y sobre la base de la memoria viva del antecedente de los años 30 y 40.

\section{Conclusiones}

El proceso abierto con la Independencia y la construcción del orden republicano reconfiguró las interrelaciones del Estado con los pueblos indígenas, legalizando su condición de ciudadanos. En torno a uno de los deberes de la ciudadanía, la prestación militar, en la Puna jujeña su rumbo fue extraordinario por la aplicación de la contribución indígena. El significado, la dimensión, la singularidad y la implicancia de este instrumento motivaron la revisión y exploración presentada en

82 Correspondencia oficial del 15 de julio de 1837, Yavi. AHJ. Caja Documento, año 1837.

83 Correspondencia oficial del 17 de agosto de 1837, Cochinoca. AHJ. Caja Documento, año 1837.

84 Correspondencia oficial del 13 de julio de 1837, Jujuy. AHJ. Caja Documento, año 1837.

85 Sesión 21 del 9 de marzo de 1863, folios 90 y siguientes. Archivo Histórico de la Legislatura de Jujuy (AHLJ), Libro de Actas Manuscritas, $\mathrm{N}^{\circ} 10$. 
este trabajo. Dos cuestiones claves nos interesó resolver. Primero, żpor qué si la guerra de la Confederación Peruano-Boliviana no comprometió mayor y militarmente a los soldados de la Puna, como se deduce de la bibliografía al respecto, la situación derivó en la creación de un mecanismo legal que precisamente sirvió para desmilitarizar la región? Segundo, ¿̇por qué el discurso de los indios de la Puna durante este proceso señaló como coyuntura especialmente adversa a sus intereses el gobierno de Pablo Alemán?

Entendemos que el fuerte intento de militarizar la Puna hacia mediados de la década de 1830, en la gobernación de Alemán, no su omisión o inexistencia, inclinó la voluntad de muchos de sus vecinos a buscar amparo al otro lado de la frontera, activando las redes parentales y económicas que tenían en algunos parajes del suelo boliviano. Al mismo instante, producto de esa experiencia de militarización, y no solo el desarrollo de la propia guerra, nació la idea de pactar un tributo que los eximiera del servicio de las armas.

Más allá de la prolongada contienda por la Independencia y la conflagración con Bolivia entre 1837 y 1839, la presencia de la guerra fue constante en la Puna, si contamos entre ellas las llamadas guerras civiles. Como hemos intentado narrar, la provincia de Jujuy fue un campo de batalla activo en estos enfrentamientos entre unitarios y federales hasta la década de 1860 inclusive; fue territorio de paso permanente de los bandos derrotados y de los emigrados políticos, a la vez que tuvo que sellar militarmente su autonomía estatal. Para la Puna y sus indígenas no fueron extraños, lejanos, ajenos, cada uno de estos sucesos. Por el contrario, en el transcurrir de los incidentes bélicos hemos procurado documentar la participación activa de estas poblaciones en distintos operativos y movilizaciones.

Además, el ordenamiento regular de los cuerpos de milicia y la impartición del disciplinamiento castrense también se hicieron efectivos en determinados momentos en esta región. Como hemos visto reflejado en números, la militarización fue un fenómeno vivido en carne propia. En la práctica, el servir en la ciudad, con la implicancia que ello conllevaba del traslado de a pie para muchos de los puneños que carecían de caballos y la ausencia prolongada de sus hogares y abandono de los quehaceres de subsistencia, fue especialmente resistido. El gran acuartelamiento citadino ordenado por Alemán en 1837, el consecuente levantamiento del batallón 
Dorrego y el desenlace de un tributo pactado fueron situaciones concretas de la experiencia militar de la Puna.

Este primer ensayo de examinar las guerras civiles como plano de visualización de la participación y agencia indígena en la Puna deja abierta una amplísima agenda a futuro, la cual se pretende seguir. Desde la discusión teórica resulta central continuar el estudio de la guerra como elemento del sistema político. Ello implica incorporar en el análisis la idea de la guerra como parte constitutiva en la construcción de los Estados republicanos del siglo XIX, es decir, como una "forma legítima de hacer política"86. Desde lo empírico, y en el primer paso, es preciso dar un rostro más humano a los números constatados de los cuadros de milicia de la Puna, reconstruir sus perfiles socioeconómicos, seguir las huellas personales de los oficiales actuantes y de sus interrelaciones con el resto del espacio social, determinar alineaciones y rivalidades políticas en la comunidad local, establecer las tramas de ese poder local y sus intermediaciones.

Fecha de recepción: 25/08/20

Aceptado para publicación: 03/02/21

86 Méndez, Cecilia y Granado Moya, Carla, "Las guerras olvidadas del Perú: formación del Estado e imaginario social", Revista de Sociología Política, Vol. 20, N 42, 2012, 57-71. 


\section{Referencias Bibliográficas}

Bacile, Clemente, Una guerra poco conocida, T. I, Universidad Nacional de Jujuy, San Salvador de Jujuy, (1943), 1993.

Bushnell, David, "La política indígena de Jujuy en época de Rosas", Revista de Historia del Derecho, $\mathrm{N}^{\circ} 25,1997,59-84$.

Conti, Viviana, 2006, "De las Guerras de la Independencia a la Organización del Estado. 1810-1852", en Teruel, Ana y Lagos, Marcelo, dir., Jujuy en la Historia. De la colonia la siglo XX, Jujuy, EdiUnju, 85-173.

Davio, Marisa, "Los sectores populares militarizados en la cultura política tucumana. 18121852", Tesis Doctoral en Ciencias Sociales, Universidad Nacional de General Sarmiento e Instituto de Desarrollo Económico y Social (IDES), Buenos Aires, 2010, https://www.ungs.edu.ar/posgrados/sectores-populares-militarizados-en-la-culturapolitica-tucumana-1812-1854, (Consultado el 17/03/019).

Delgado, Fanny, "Ingresos Fiscales de la Provincia de Jujuy (1834-1852)”, en Data, N², 1992, 97-115.

Delgado, Fanny, "La ciudadanía en el sector norte del Territorio Nacional de los Andes (Susques), perspectiva indígena- perspectiva estatal", en Plataforma del Programa Interuniversitario de Historia Política, $\mathrm{N}^{\circ} \quad 6, \quad 2010$, http://www.historiapolitica.com/dossiers/territorios/ (Consultado el 21/01/2021).

Di Meglio, Gabriel, "La Guerra de Independencia en la Historiografía Argentina", Plataforma del Programa Interuniversitario de Historia Política, $\mathrm{N}^{\circ}$. 7, 2010, 1-26, http://www.historiapolitica.com/dossiers/lasguerras/, (Consultado el 20/01/2021).

Fandos, Cecilia, "Entre la Guerra del Paraguay y el levantamiento de Varela: manifestaciones socioeconómicas en Jujuy a mediados del siglo XIX", Quinto Sol, Vol. $23, \mathrm{~N}^{\circ} 2,2019,1-20$.

Fandos, Cecilia, "Viva la Santa Federación, mueran los salvajes unitarios'. El régimen rosista, los subdelegados y el gobierno de la Puna jujeña en la década de 1840", en Gutiérrez, Mirta y Citterio, Diego, comp., Historias breves de Jujuy II. Actores y prácticas de poder en los siglos XIX y XX, Cuadernos del Duende, San Salvador de Jujuy, 2019, 66-75.

Fandos, Cecilia, "Bajar a servir en la Ciudad de Jujuy. Servicios ciudadanos y resistencia indígena en la temprana República (1840-1860), en Estudios Sociales del NOA", № 22, 2019, 117-141.

Fradkin, Raúl, "Cultura política y acción colectiva en Buenos Aires (1806-1829): Un ejercicio de exploración”, en Fradkin, Raúl ed., ¿Y el pueblo dónde está? Contribuciones para una historia popular de la revolución de independencia en el Río de la Plata, Prometeo, Buenos Aires, 2008, 27-66. 
Fradkin, Raúl, “Tradiciones militares coloniales. El Río de La Plata antes de la Revolución”, en Heinz, F., comp., Experiências nacionais, temas transversais: subsídios para uma história comparada da América Latina, Editora Oikos, São Leopoldo, 2009, 74-126.

Gil Montero, Raquel, "Guerras, hombres y ganado en la Puna de Jujuy: Comienzos del Siglo XIX”, en Boletín del Instituto de Historia Argentina y Americana Dr. Emilio Ravignani, $\mathrm{N}^{\circ} 25,2004,9-36$.

Gil Montero, Raquel, "Tierras y tributo en la Puna de Jujuy. Siglos XVIII y XIX”, en Farberman, Judith y Gil Montero, Raquel, comp., Los pueblos de indios del Tucumán Colonial, pervivencia y desestructuración, EDIUNju/ Universidad Nacional de Quilmes Ediciones, Argentina, 2002, 227-255.

Gil Montero, Raquel, "La Puna: población, recursos y estrategias”, en Teruel, A. y Lagos, M., direc, Jujuy en la Historia. De la colonia al siglo XX, Jujuy, EDIUNJu, 2006, $375-$ 401.

Irurozqui, Marta, “¿Ciudadanos armados o traidores a la patria? Participación indígena en las revoluciones bolivianas de 1870 y 1899", Iconos. Revista de Ciencias Sociales, $\mathrm{N}^{\circ}$ $26,2006,35-46$.

Macías, Flavia, "Introducción al dossier Las milicias en acción. Revoluciones, elecciones y ejército en la Argentina de la segunda mitad del siglo XIX", Plataforma del Programa Interuniversitario de Historia Política, $\mathrm{N}^{\circ} \quad 17, \quad 2011$, http://www.historiapolitica.com/dossiers/dossiermilicias/ (Consultado el 14/09/2019).

Madrazo, Guillermo, Hacienda y encomienda en los Andes. La Puna de Jujuy bajo el marquesado de Tojo, siglos XVII-XIX, Fondo Editorial, Buenos Aires, 1982.

Mata de López, Sara, "Guerra, Militarización y Poder. Ejército y Milicia en Salta y en Jujuy. 1810- 1816”, Anuario IEHS, 24, 2009, 279-298.

Méndez, Cecilia y Granado Moya, Carla, "Las guerras olvidadas del Perú: formación del Estado e imaginario social", Revista de Sociología Política, Vol. 20, N 42, 2012, 57 71.

Méndez, Cecilia, "Tradiciones liberales en los Andes o la ciudadanía por las armas: campesinos y militares en la formación del estado peruano", en Irurozqui Victoriano, Marta, ed., La mirada esquiva. Reflexiones históricas sobre la interacción del estado y la ciudadanía en los Andes (Bolivia, Ecuador y Perú), siglo XIX, Consejo Superior de Investigaciones Científicas, Madrid, 2005, 125-153.

Morán, Daniel, "La historiografía de la revolución. La participación plebeya durante las guerras de independencia en el Perú y el Río de la Plata", Nuevo Mundo Mundos Nuevos. 2011, http://nuevomundo.revues.org/61404 (Consultado el 6 de octubre de 2017).

Pavoni, Norma, El Noroeste Argentino en la época de la Alejandro Heredia, Fundación Banco Comercial del Norte, Tucumán, Tomo 1, 1981.

Paz, Gustavo, Las Guerras Civiles (1820-1870), Eudeba, 2007. 
Paz, Gustavo, "Reordenando la campaña: la restauración del orden en Salta y Jujuy, 18221825”, en Fradkin, Raúl, ed., ¿Y el pueblo dónde está? Contribuciones para una historia popular de la revolución de independencia en el Río de la Plata, Prometeo, Buenos Aires, 2008, 209-222.

Paz, Gustavo, “Auge y caída del 'comunismo indígena' en el Norte argentino: los Andes de Jujuy, 1830- 1900”, en Di Meglio, Gabriel y Fradkin, Raúl, comp., Hacer política. La participación popular en el siglo XIX rioplantese, Prometeo, Buenos Aires, 2013, 93116.

Paz, Gustavo, "El orden es el desorden”. Guerra y movilización campesina en la campaña de Jujuy. 1815-1821”, Plataforma del Programa Interuniversitario de Historia Política, $\mathrm{N}^{\circ}$ 7, 2010, http://www.historiapolitica.com/dossiers/lasguerras/ (Consultado el 20/05/2019).

Platt, Tristan, Estado boliviano y ayllu andino. Tierra y tributo en el Norte de Potosí, Instituto de Estudios Peruanos, Lima, 1982.

Quijada, Mónica, "La caja de Pandora. El sujeto político indígena en la construcción del orden liberal", Historia Contemporánea, N³3, 2006, 605-637.

Rabinovich, Alejandro, "La militarización del Río de la Plata, 1810-1820. Elementos cuantitativos y conceptuales para un análisis", Boletín del Instituto de Historia Argentina y Americana Dr. Emilio Ravignani, $\mathrm{N}^{\circ} 37,2012,11-42$.

Sánchez, Matías, Nación e Identidad durante la Guerra de la Confederación Peruano Boliviana (1836-1839). La Puna y la Quebrada de Humahuaca (Jujuy, Argentina), Imprenta Lukar/ Purmamarca Ediciones, S.S de Jujuy, 2017.

Schmit, Roberto, “Argentina en el mundo (1830-1880)”, en Fradkin, Raúl y Garavaglia, Juan Carlos, coord., Argentina. La construcción Nacional, tomo 2, Mapfre, Madrid, 2012, 225-306.

Sica, Gabriela, "Las otras mitas. Aproximaciones al estudio de la mita de plaza en la Jurisdicción de Jujuy, gobernación de Tucumán, siglo XVII", Anuarios de Estudios Americanos, 71, 1, 2014, 201-226.

Vergara, Miguel Angel, Jujuy bajo el signo federal, Edición Oficial del Gobierno de Jujuy, Imprenta del Estado, 1938.

Walker, Charles, "Los indios en la transición de colonia a república: ¿Base social de la modernización política?", en Urbano, Henrique, ed., Tradición y modernidad en los Andes, Centro de Estudios Regionales Andinos "Bartolomé de Las Casas", Cuzco, 1997, 1-14. 